Artículo de investigación

Apuntes del CENES

ISSN 0120-3053

Volumen $33-\mathrm{N}^{\circ} .58$

Julio - Diciembre de 2014

Págs. 45-82

\title{
Dinámica económica de las remesas enviadas desde España y Estados Unidos a Colombia entre 2005- 2013: un análisis de cointegración
}

\author{
Economic dynamic of remittances sent from \\ Spain and the United States to Colombia \\ between 2005-2013: An analysis of \\ cointegration
}

Andrés Mauricio Gómez Sánchez*

Zoraida Ramírez Gutiérrez**

Fecha de recepción: 22 de enero de 2014

Concepto de evaluación: 7 de febrero de 2014

Fecha de aprobación: 15 de septiembre de 2014

Magíster en Economía Aplicada, Universidad del Valle, Colombia. Profesor titular, Departamento de Economía, Universidad del Cauca. Cauca, Popayán, Colombia. Correo electrónico: amgomez@unicauca.edu.co

** Magíster en Administración Económica y Financiera, Universidad Tecnológica de Pereira. Profesora asociada, Departamento de Contaduría, Universidad del Cauca. Cauca, Popayán, Colombia. Correo electrónico: zramirez@ unicauca.edu.co 
Dinámica económica de las remesas enviadas desde España y Estados Unidos a Colombia ...

Andrés Mauricio Gómez Sánchez - Zoraida Ramírez Gutiérrez

\section{Resumen}

El propósito del artículo es analizar el comportamiento de las remesas enviadas desde España y Estados Unidos hacia Colombia en los últimos nueve años, y buscar específicamente cuáles son sus determinantes a largo plazo. Para lograrlo se implementa un análisis de cointegración convalidado con un método de corrección de errores. Se encuentra que las series bajo análisis tanto para España como para Estados Unidos están cointegradas, es decir hay relaciones estables de largo plazo entre las remesas, el PIB, el desempleo y el tipo de cambio, aunque la velocidad de convergencia entre el corto y largo plazo de dicha relación es alta para Estados Unidos y más lenta para España.

Palabras clave: remesas, cointegración, mecanismo de corrección de errores, estabilidad a largo plazo.

JEL: C01, C22, F22, F24.

\section{Abstract}

The purpose of this paper is to analyze the behavior of remittances from Spain and the United States to Colombia in the last nine years, searching specifically what its long-term determinants are. To achieve it, cointegration analysis validated with an error correction method is implemented. It is found that the series under analysis for both Spain and the United States are cointegrated, i.e. there are stable long-term relationships between remittances, GDP, unemployment and the exchange rate, although the rate of convergence between the short and long term within this ratio is high for the U.S. and slower for Spain.

Keywords: remittances, cointegration, error correction model, long-run stability. 


\section{INTRODUCCIÓN}

Las remesas, entendidas como el dinero enviado por parte de emigrantes a su país de origen, han cobrado un especial protagonismo en la esfera de las economías mundiales, pero sobre todo en las latinoamericanas. De acuerdo con el BID (2007, p. 9), en América Latina las remesas crecieron a tasas de doble dígito durante la mayor parte de la primera década del nuevo milenio. En Colombia, las cifras del Banco de la República muestran que bajo el periodo analizado, su comportamiento en términos reales fue muy dinámico pero posteriormente perdió fuerza, pues se pasó de recibir USD 4.784 millones entre 2005 y 2008, a USD 3.969 millones en 2013.

En los últimos cinco años (2009-2013) la tendencia se ha modificado debido básicamente a la crisis financiera global que dejó sin empleo a muchos emisores de estos flujos de capital, y repercutió de forma negativa frente al envío de remesas en países como México, Colombia, Guatemala, Brasil, y Ecuador, entre otros. Para el caso de Colombia, la crisis económica que atravesaron Estados Unidos y España, principales emisores de remesas hacia nuestro país, ha afectado su economía regional, primordialmente al Eje Cafetero y Valle del Cauca. Aunque después del estallido de la crisis, los envíos han disminuido en promedio un $4.4 \%$, todavía se siguen manteniendo como un rubro importante en la economía nacional (5\% de los ingresos por cuenta corriente), ya que los emisores siguen enviando dinero a pesar de la crisis (sobre todo desde España), fundamentalmente de las mujeres que son contratadas como empleadas o niñeras. 
A pesar de todo lo anterior, las remesas se han constituido en ingresos permanentes para las familias colombianas, quienes las utilizan en su mayoría para consumo $\mathrm{y}$ en una menor proporción para ahorro e inversión (BID, 2007, p. 19). Es decir, dichos flujos se han constituido en un ingreso de vital importancia para el sostenimiento de muchas familias en nuestro país. La determinación del porqué los colombianos envían remesas a sus familiares en Colombia es simple: en algunos casos, se intenta mejorar o mantener su calidad de vida y, en otros casos, generar ahorros para luego comprar o invertir en bienes o servicios. Pero más allá de los lazos estrictamente familiares o afectivos, o de los intereses personales de diversa índole, deben existir otros aspectos de carácter económico y social que no se pueden pasar por alto a la hora de enviar dichos recursos.

Por ejemplo, en la balanza de pagos se encuentra que en promedio el $72.1 \%$ de las remesas han sido enviadas desde España y Estados Unidos en los últimos nueve años, lo que coincide con que bajo el mismo periodo estos dos países fueron los principales destinos migratorios de los colombianos. Desde este punto de vista, el envío de remesas a cualquier destino está fuertemente ligado al fenómeno migratorio, constituyéndose en una variable netamente de carácter social. Al igual podrían sumarse otras de carácter económico como por ejemplo el ciclo económico, ya que se supone que bajo recesiones, el envío de dinero es escaso y, por el contrario, abundante en las expansiones.

En general, los estudios respecto del tema, por lo menos para Colombia, tales como los de Roa (2011), BID (2007); Garay y Rodríguez (2005), han sido de carácter descriptivo y con enfoques orientados más hacia los aspectos contables, legales y sociales. Otros se han enfocado en temas económicos muy particulares relacionando las remesas con la participación laboral, con su impacto en el Eje Cafetero, o con el crecimiento económico, como los realizados por Arango, Montenegro y Obando (2011); Romero y Salinas (2010); Mora, (2008); Sinisterra, (2005). Pero en ellos poco se ha dicho sobre los determinantes estructurales que condicionan el envío de las remesas a nuestro país. Con esta orientación se permite vislumbrar no solo cuáles son las razones económicas que tienen los emigrantes para enviar dinero, sino también anticipar cuáles serán los comportamientos cíclicos de los envíos y cómo será su impacto en el medio y largo plazo en nuestro país. Proceso que a su vez podría servir para los responsables de la política pública para tomar medidas de choque en regiones o ciudades donde el envío de remesas tiene una alta participación en el nivel de actividad económica, tal como sucede en el Área Metropolitana Centro Occidente -AMCO-.

En este orden de ideas, en este documento se implementa un análisis de órdenes de integración con datos a precios constantes 
de 2005, la estimación de un modelo cointegrante y su validación a través de un método de corrección de errores para capturar dicha dinámica. El objetivo por tanto es establecer el impacto de los factores mencionados anteriormente sobre las remesas, bajo un análisis previo de cointegración para develar la existencia de relaciones estables de largo plazo entre ellas y determinar si la velocidad de ajuste en el corto plazo a la tendencia de largo plazo es alta o baja a través de un mecanismo de corrección de errores.

En este orden de consideraciones, el documento consta de cinco partes: la primera, que es esta introducción; la segunda, que presenta no solo la teoría relacionada con las migraciones, sino que tendrá en cuenta la referencia de algunos estudios; la tercera, en la cual se analiza de forma descriptiva la evolución de las remesas en Colombia; la cuarta, en la que se implementa la econometría del caso, y finalmente, la quinta, en la que se establecen algunas conclusiones y recomendaciones.

\section{REFERENTES TEÓRICOS Y ESTUDIOS APLICADOS}

Las explicaciones del envío de las remesas hacia cualquier destino vienen generalmente dadas por factores de índole económico y social. Desde la economía, Garay y Rodríguez (2005), Mora (2008) y García (2010), coinciden en que dentro de los aspectos económicos que tienen en cuenta los nacionales en el exterior para el envío de dichos recursos está el comportamiento del PIB por lo menos del país expulsor. De esta manera se considera que el PIB es una señal que motiva el envío de remesas, ya que el nivel de actividad económica de los países, sus expansiones y recesiones, condiciona la oferta y la demanda de las mismas. Siguiendo a García (2010), esta relación obedece, dicho sea de paso, al fracaso del modelo neoliberal:

La evolución económica de América Latina (AL) durante finales del siglo XX e inicio del siglo XXI muestra cómo, en la medida en que se fueron desmantelando los diversos proyectos nacionales de desarrollo, en que el Estado dejó de ser el promotor de ese desarrollo y del bienestar de la población, delegando la conducción de sus economías en manos de los organismos internacionales como el Fondo Monetario Internacional (FMI), el Banco Mundial (BM) y la oligarquía financiera internacional - aliada con las oligarquías nacionales-, las crisis económicas se volvieron crónicas y con ellas las migraciones internacionales se volvieron explosivas desde los años noventa del siglo anterior. Bajo el modelo neoliberal en curso se pensó que esas migraciones resultaban funcionales al mismo modelo, ya que actuaban como como «válvula de escape» a una población laboral que crecientemente no podía ser absorbida decorosamente en sus países de origen, contribuía a 
satisfacer la demanda laboral en los países de destino en expansión y además generaba importantes flujos de remesas familiares con significativos efectos macroeconómicos, a nivel nacional, regional y familiar. (García, 2010, p. 120-121).

Otro factor por considerar es el desempleo nacional, aunque frente a esta relación existen varias hipótesis de comportamiento en una prolífica discusión al respecto. Arango et al. (2011), afirman que el envío de remesas es un incentivo para buscar o no trabajo y les sirve a los hogares de colchón cuando hay recesión:

Al disminuir los recursos que reciben los hogares en Colombia por concepto de remesas enviadas por sus familiares, algunos integrantes de dichos hogares se han visto en la necesidad de salir a trabajar o a buscar una ocupación; en eso consiste al aumento de la participación laboral. Las remesas reducen los incentivos a participar en el mercado de trabajo por el aumento del salario de reserva de los trabajadores secundarios del hogar y el aumento de la probabilidad de desánimo de los desocupados. Las remesas permiten también a sus receptores financiar períodos de tiempo más largos de búsqueda de empleo, lo cual debería reducir los niveles de subempleo por ingresos y competencias en el mediano y largo plazo (Garay y Rodríguez,
2005). Así mismo, las remesas son utilizadas por las familias para cubrir necesidades básicas de alimentación, educación, vivienda, etc., además de constituir una fuente alterna de ingresos durante las fases de recesión del ciclo económico (Cadena y Cárdenas, 2004). (Arango et al., 2011, p. 1-2).

Aunque Mora (2007) ya había probado esta hipótesis para la ciudad de Cali, encontrando que efectivamente a los beneficiarios de las remesas se les reduce los incentivos para participar en el mercado laboral. De otro lado, Montoya et al. (2010) aseguran que el ingreso de remesas a nuestro país impulsa el empleo y disminuye la pobreza, ya que se orientan dichos recursos a la compra de bienes inmuebles:

Con miras a optimizar el uso de estos dineros, la reducción de costos de transacción para el envío de remesas y la creación de cooperativas financieras apuntan a maximizar el impacto de las remesas a través del sistema financiero (Castañeda, 2006) pero hay proyectos como Mi Casa con Remesas de las cajas de compensación de Colombia que han apuntado a canalizar las remesas hacia la compra de vivienda con el propósito de disminuir el desempleo y reducir la pobreza. (Montoya et al., 2010, p. 65-66).

En este estudio se considera un enfoque distinto, pues el desempleo, coadyuvado 
por la falta de oportunidades laborales, y bajos salarios a nivel local y altos a nivel internacional, se constituye en una fuerte razón para migrar a otros países donde la situación económica es mejor, con el objetivo de enviar dinero a las familias que quedan atrás.

De otro lado, Castillo (2001) también contempla la posibilidad de que el tipo de cambio sea un factor clave para el envío de dichos recursos en dos niveles para el caso mexicano. Inicialmente, dado que la capacidad adquisitiva del giro implica mayores o menores esfuerzos económicos por parte de quien envía la remesa. Es decir, en periodos de revaluación del peso colombiano, se deben enviar menos dólares (euros), y en temporadas de devaluación, más dólares (euros). Finalmente, podría percibirse la devaluación como una oportunidad de mandar más remesas para obtener un mayor ingreso real en los giros:

Es razonable argumentar que una devaluación del peso conllevaría a incrementar el poder adquisitivo de aquel sector de la población que percibe sus ingresos en dólares. Esto es, los familiares en México de los migrantes radicados en Estados Unidos necesitarían menos dólares para obtener su canasta de consumo, por lo que esperaríamos un decremento en el monto de las remesas en respuesta a una devaluación de la moneda. (Castillo, 2001, p. 38).
Adicionalmente, señala este autor:

Por otra parte, el hecho de que se haya incrementado el poder adquisitivo de los familiares en México podría representaruna posibilidad de aumentar su consumo (efecto riqueza) y adquirir un mayor número de bienes. Podrían, por ejemplo, construir una casa de dos, en lugar de una, recamaras. En ese caso, una depreciación de la moneda resultaría en un incremento en el flujo de remesas. (Castillo, 2001, p. 38).

Otra perspectiva de la relación entre el tipo de cambio y las remesas, la presenta Roca (2009), ya que considera que las remesas tienen un impacto de carácter macroeconómico diferencial, dependiendo de si el tipo de cambio es fijo o flexible. Frente al tipo de cambio fijo, asegura que:

Una mayor entrada de divisas por remesas provenientes del exterior eleva el ingreso disponible aumentando la demanda agregada por otro lado se incrementa la oferta de divisas lo cual genera presiones a la baja al tipo de cambio lo que obliga al Banco Central a comprar divisas para que se mantenga el tipo de cambio por lo que aumenta endógenamente la oferta monetaria reforzando el efecto expansivo. (Roca, 2009, p. 3)

Para el tipo de cambio flexible, muestra que: 
Dinámica económica de las remesas enviadas desde España y Estados Unidos a Colombia ...

Andrés Mauricio Gómez Sánchez - Zoraida Ramírez Gutiérrez

Una mayor entrada de divisas por remesas provenientes del exterior tiene un efecto neto negativo sobre el nivel de producción de equilibrio de corto plazo. Si bien al incrementarse las remesas al país aumenta el ingreso disponible dicha entrada de divisas aumenta la oferta de divisas reduce el tipo de cambio y deteriora las exportaciones netas lo cual es más fuerte que el efecto sobre el consumo por lo que en neto cae el nivel de producción a acorto plazo. (Roca, 2009, p. 4)

Otra variable por considerar, aunque no es netamente económica sino de carácter social, son los fenómenos migratorios. En efecto, de acuerdo con Garay y Rodríguez (2005), Lozano (2008), Cerruti y Maguid (2011), consideran que las migraciones también están estrechamente ligadas al envío de remesas. Siguiendo a Garay y Rodríguez (2005), se encuentra que

Ante estas circunstancias, no cabe duda alguna de la conveniencia de profundizar en el análisis de los impactos de la migración internacional y de las remesas en el bienestar y calidad de vida de los protagonistas (individuos, hogares y comunidades tanto en el país de origen como de destino) y en el desarrollo económico y social no solo a nivel nacional sino también a nivel de las regiones y localidades de origen con elevada migración internacional». (p 60).

En efecto, esto sucede básicamente porque la situación económica de los países emergentes no es la mejor, ya sea por bajos salarios o escasas oportunidades de emplearse, lo que induce a migrar hacia países desarrollados en busca de mejorar su propia situación económica y posteriormente la de sus familias, a través del envío de dinero en forma de remesas una vez han podido obtener un trabajo. Los autores reconocen que existen otros fenómenos como la reunificación familiar, o la oferta de estudios en educación superior ${ }^{1}$.

Frente al tema, Lozano (2008) implementó un modelo logístico donde la variable dependiente es si el migrante envía o no remesas a su país de origen, lo cual es explicado por 18 variables explicativas de carácter socioeconómico para toda Latinoamérica (exceptuando Puerto Rico). Los resultados indican, entre otras cosas, que la probabilidad de que los emigrantes del Caribe envíen remesas desde Estados Unidos es $80 \%$ mayor

\footnotetext{
El mayor número de emigrantes colombianos, de acuerdo con la Organización Internacional para las Migraciones (OIM), se ha dirigido en los últimos diez años hacia Estados Unidos (34.6\%) y hacia España (23.1\%). Es decir, más de la mitad del total de emigrantes se dirigen hacia estos dos países. La mayor proporción (63,6 \%) de los remitentes emigró durante el último quinquenio (2000-2004), mientras que el 19,2\% lo hizo entre 1995 y 1999 . Se observa una mayor participación relativa de las mujeres (cerca del 48,7 \% son hombres). El 93,5\% de los remitentes es económicamente activo (trabaja o busca empleo). El 70,5 \% tiene educación secundaria completa o superior, porcentaje significativamente superior al de los receptores con el 58,6 \%. (Garay \& Rodríguez, 2005, p. 35).
} 
que entre los emigrantes de México que son utilizados como categoría base. Los emigrantes centroamericanos son $72 \%$ más proclives a mandar remesas que los mexicanos. Finalmente, aunque entre los emigrantes sudamericanos la probabilidad de hacer envíos de remesas es un $10 \%$ menor que en la categoría de referencia, esta diferencia no resultó estadísticamente significativa.

Vale la pena mencionar que Sinisterra (2005, p. 85-86) parafraseando a Faini (2002), dice que la relación encontrada por este último entre las remesas y la migración no es tan clara, ya que, de acuerdo con su estudio, un volumen mayor de emigrantes calificados está asociado con un flujo menor de remesas. Pero la pregunta que subyace es si los emigrantes colombianos tienen un alto grado de cualificación. La evidencia empírica de acuerdo con las cifras del BID (2007, p. 26), muestra que no es así, ya que los emigrantes generalmente son personas con bajos niveles de educación, alcanzando la secundaria solo el $31 \%$ y la universitaria superior o universitaria el $28 \%$, por lo que el restante $\$ 41 \%$ solo tiene primaria, algún o ningún tipo de estudio. Así las cosas, parece ser que la hipótesis correcta debe ser la contraria del autor en mención, es decir, un volumen mayor de emigrantes no calificados está asociado con un flujo mayor de remesas.

Los estudios sobre remesas a nivel nacional muestran diferentes perspectivas sobre el particular, pero construidos bajo un denominador común, y es su carácter descriptivo analítico desde la economía.
Una primera aproximación es realizada por Garay y Rodríguez (2005). En este documento, las migraciones son abordadas en primera medida por un contexto teórico desde las diferentes escuelas de pensamiento económico, al igual que desde la historia, la antropología, la historia, la ciencia política y la psicología. El esfuerzo es muy valioso y novedoso, pues muestra un análisis desde diferentes disciplinas de dichos flujos de capital. El estudio también se centra en las características de la dinámica de las remesas en Colombia desde 1996 a 2004. En esta parte define los perfiles de los emisores y de los receptores, al igual que el uso y la destinación de las mismas. Concluye que las regiones con mayor participación en la recepción de remesas son la del Pacífico, con el $32 \%$, el Eje Cafetero, con $19 \%$, y Bogotá, con $16 \%$. Adicionalmente, el estudio halla que 80 de cada 100 remitentes de remesas que residen en España, emigraron entre 2000 y 2004, y para el caso de los residentes en Estados Unidos, la cifra fue de 54 de cada 100 remitentes.

Otro esfuerzo fue realizado por la Organización Internacional para las Migraciones -OIM- también en el año 2005. Desde un primer análisis se muestra la relación de la OIM con los flujos migratorios y las remesas en América Latina y el Caribe. Se indica que la migración obedece a factores de carácter laboral y forma parte de la dinámica regional que puede ser altamente beneficiosa, si es negociada con los asociados concernidos y puede tener un gran potencial siempre y cuando 
sea bien encausada. En otro análisis, se construye por un lado una metodología de medición de la migración con todos sus soportes técnicos documentados que incluyen la descripción de sus procesos y procedimientos, y de otro una metodología que asegurara disponer oportunamente de estadísticas sobre emigración.

Seguidamente se hace otro análisis desde el punto de vista socioeconómico de los emigrantes procedentes del Área Metropolitana Centro Occidente -AMCO-, en donde se encuentra, por ejemplo, que las altas tasas de desempleo, la destrucción de puestos de trabajo y la reducción de los ingresos de los hogares, ocurridas a partir del segundo quinquenio de los noventa, podrían haber sido causas determinantes de la emigración de muchos colombianos al exterior; y ya desde el mercado laboral se llega a develar que la tasa global de participación -TGP-y el desempleo, son ostensiblemente inferiores para las personas que reciben remesas. La brecha en la TGP entre receptores y no receptores es de 10 puntos a favor de los no receptores, mientras que la tasa de desempleo de los no receptores duplica la de los receptores.

En el año 2007, el Banco Interamericano de Desarrollo -BID- realiza un barrido extenso sobre lo que rodea la dinámica de las remesas, pero con un bajo contenido económico (que se centra en lo coyuntural descriptivo) y hace más énfasis en aspectos como el carácter legal, los proveedores de servicios de remesas a nivel internacional, los medios de pago y los canales para la transferencias, al igual que los costos y la metodología para medirlas. En el aspecto económico encuentra, entre otras cosas, que en términos de los ingresos corrientes de la balanza de pagos, en 2006 los ingresos por remesas fueron equivalentes al $11.1 \%$ y $15.4 \%$ de las exportaciones de bienes, y con respecto a los ingresos corrientes de la balanza de pagos, su importancia relativa fue de $57.6 \%$, por lo que se concluye que las remesas de los trabajadores se han constituido en la segunda fuente de recursos menos volátil que la IED.

Un estudio encaminado a mostrar los impactos de las migraciones y las remesas en el crecimiento económico fue realizado por Sinisterra (2005), en el que básicamente se intenta mostrar las principales causas y efectos económicos de la migración laboral internacional. Partiendo de la teoría neoclásica del comercio internacional y basada en el modelo de Heckscher-Ohlin (1933) y Mundell (1957), se muestra como la movilidad internacional del trabajo genera crecimiento económico en el país destino al aumentar la cantidad del factor intensivo en el bien que exporta (efecto Rybczynski) y en el de origen al aumentar los ingresos de las familias y por tanto el consumo y la inversión. Debido a esta importancia, se requiere de una política pública para reducir los costos de transacción que impiden el mayor flujo de las remesas. 
Otro estudio un poco más focalizado con información primaria, lo constituye el realizado por Roa (2011), el cual muestra cuál es el uso de las remesas enviadas desde España que se hace en la región del Pacífico. Utilizando una encuesta y un método netamente descriptivo, el estudio concluye fundamentalmente que los hogares utilizan estos dineros prioritariamente en alimentación, pago de servicios públicos, educación y salud, adicionalmente existe evidencia de que las remesas procedentes de España presentan un mayor efecto redistributivo que el resto del país, porque tienen el más alto número de remitentes, menores montos de remesas y cubre mayormente las necesidades del hogar relacionadas con alimentación, servicios públicos, educación y salud. Por tanto, es un paliativo contra la pobreza de los hogares.

Cabe mencionar que si bien es cierto el análisis de las migraciones y las remesas ha sido abordado desde diferentes perspectivas y desde diversas disciplinas, siguiendo a Garay y Rodríguez (2005) no existe un análisis interdisciplinario consolidado, toda vez que áreas como la ciencia política y la psicología han llegado tarde al debate. Por tanto, frente a los estudios sobre migraciones: "Debe relacionarse estrechamente con teorías sobre etnicidad, identidad, derechos humanos y cívicos, ciudadanía, (...) sobre comunidad, Nación y Estado". (Hammar, 2000, citado por Garay \& Rodríguez, 2005, p. 25-26)
Otros autores como Hagen-Zanker $(2008,19)$, consideran que el fenómeno migratorio debe ser analizado en tres niveles: micro, meso y macro. En el primero, la migración obedece a aspectos propios del individuo y de la familia, como por ejemplo, sus niveles de estudio o género; el segundo pasa por aspectos de redes migratorias, institucionalidad migratoria, entre otras y el componente macro, donde se ubican fenómenos como el desempleo, los niveles de crecimiento y desarrollo del país expulsor, etc. En esta amplia gama de aportes, posiblemente otros que deban tenerse en cuenta son, por ejemplo, el fenómeno de estabilidad e ideología política del país de destino, la facilidad para legalizar su estadía en el país de destino, patrones culturales que identifican al fenómeno migratorio con el país de destino, los criterios de seguridad ciudadana que el nacional tiene en cuenta al momento de viajar y de posteriormente hacer la remesa.

Finalmente, el único estudio encontrado que se realizó desde la econometría fue el construido por Castillo (2001). En este documento se hace un análisis de cointegración, el cual establece que existe una relación de largo plazo entre las remesas, el PIB de Estados Unidos, el PIB de México y el tipo de cambio real. Además de establecer que las variables consideradas están cointegradas, el texto muestra un pronóstico del efecto que las modificaciones en el entorno macroeconómico mexicano y estadounidense tendrían en la cantidad de las remesas. 


\section{EVOLUCIÓN DE LAS REMESAS EN COLOMBIA}

\section{Importancia de las remesas en la economía nacional}

A partir de 2005, las remesas que ingresan a Colombia desde diferentes destinos han tenido una importancia considerable en el nivel de actividad económica. Como porcentaje del PIB, su participación trimestral pasó de ser del $0.3 \%$ a casi el $0.45 \%$, de acuerdo con la Figura 1 en su etapa de auge, aunque en términos comparativos con el inicio de la década del nuevo milenio, estas han caído, pues se registraba una participación superior al $1 \%$, según el Banco Interamericano de Desarrollo-BID-(2007, p.16). Hay que destacar también que a partir del segundo trimestre de 2008 la participación ha sido cada vez menor, llegando tan solo al 0.24 $\%$ para el segundo trimestre de 2013.

Las remesas se han constituido en ingresos permanentes para las familias receptoras, las cuales las destinan en general para consumo, ahorro e inversión. En el campo financiero, las remesas ocupan el $49.3 \%$ de la inversión exterior directa-IED-en promedio para el periodo analizado. La estabilidad de las remesas en el tiempo, de acuerdo con sus tasas de variación, se hace evidente en la siguiente figura, frente a otras inversiones tanto de corto plazo (inversión extranjera en portafolio -IEP-) como de largo plazo (inversión exterior directa).

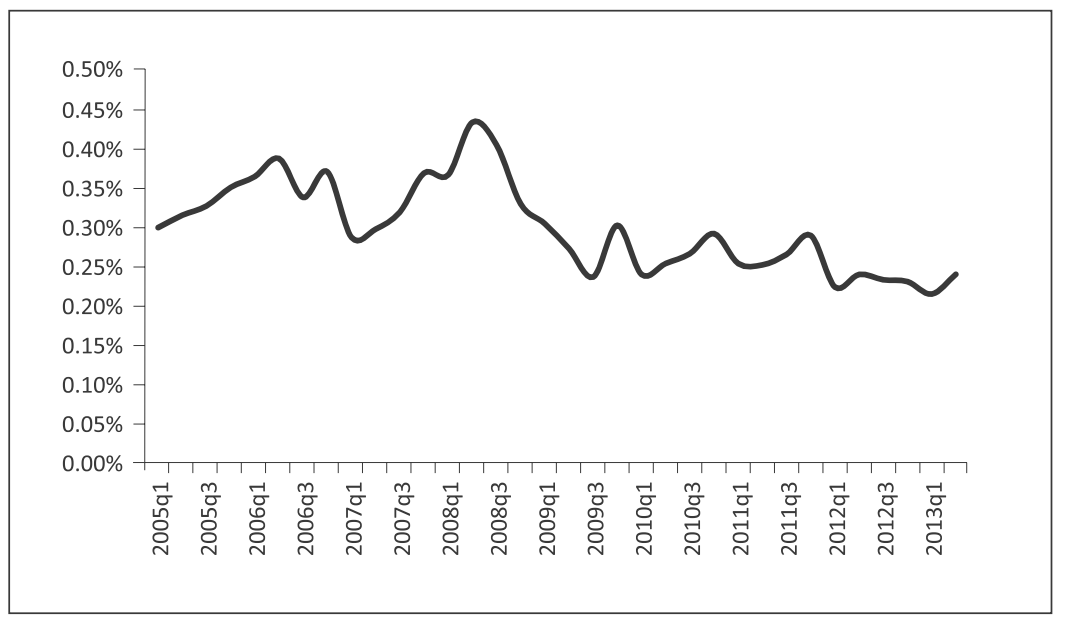

Figura 1. Participación trimestral de las remesas en el PIB de Colombia. 2005:1-2013:2. Millones de USD (2005=100).

Fuente: Cálculos propios con base en datos del DANE y Banco de la República. 
En efecto, la IEP muestra grandes saltos por la influencia que recibe de los saltos no solo de la tasa de interés sino del tipo de cambio en el corto plazo, mientras que la IED muestra una menor volatilidad por ser inversiones de bajo riesgo. Frente a las remesas, su comportamiento es el más estable de todas, y muestra que si bien es cierto deben existir variables sociales y económicas que influyen a la hora de los envíos, estos se realizan posiblemente con algún grado de independencia de dichas variables. Esto evidencia que los giros guardan un alto grado de estabilidad temporal y por tanto es una inversión más estable que la inversión realizada en otro tipo de inversiones extranjeras.

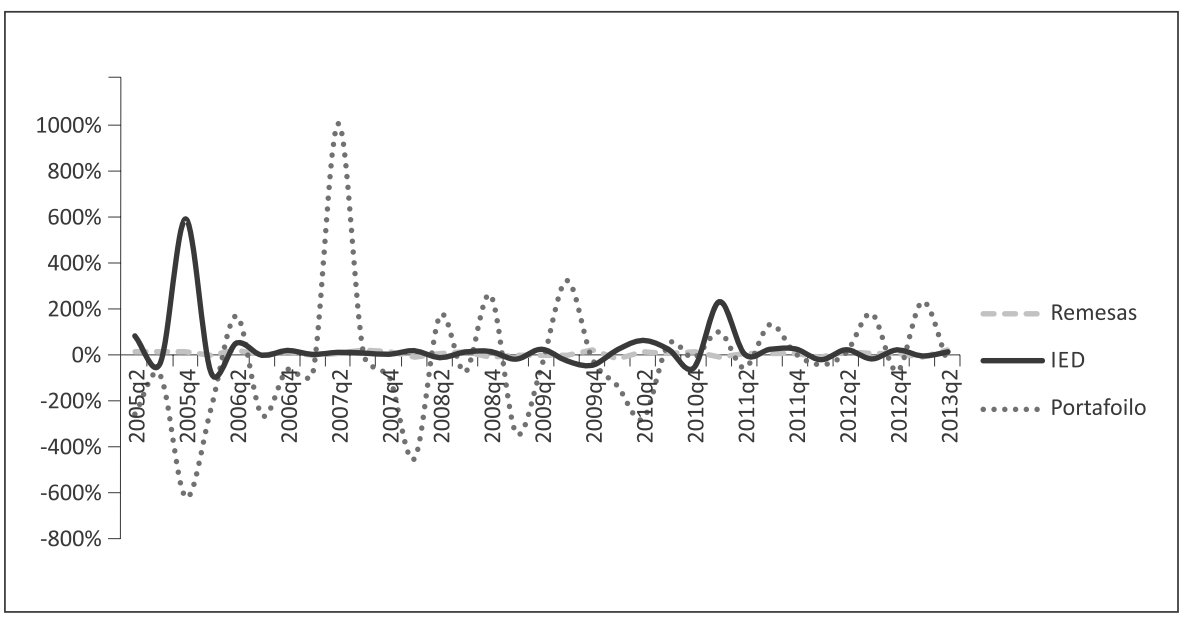

Figura 2. Variación trimestral de las remesas, inversión extranjera en Portafolio y la IED. Colombia. 2005:1-2013:2. Millones de USD (2005=100).

Fuente: cálculos propios con base en datos del DANE y Banco de la República.

\section{Comportamiento de las remesas enviadas desde España y Estados Unidos}

En Colombia, el ingreso de dineros procedentes del exterior (incluyendo las remesas) está regulado por el régimen cambiario $^{2}$. De acuerdo con la Resolución 8 de 2000 de la Junta Directiva del Banco de la República, artículo 58, los bancos comerciales y las casas de cambio están habilitados para la recepción y despacho de dichos recursos. La tendencia en nuestro país, debido a la baja

\footnotetext{
Dicho régimen está constituido por la Ley $9^{a}$ de 1991, las resoluciones que expide la Junta Directiva del Banco de la República como autoridad crediticia, monetaria y cambiaria en razón de las facultades otorgadas a esta por la Ley 31 de 1992, actualmente Resolución 8 de 2000, y por el Régimen de Inversiones Internacionales, contenido en el Decreto 2080 de 2000, modificado por el Decreto 1844 de 2003, ambos del Departamento Nacional de Planeación.
} 
bancarización de las personas receptoras, es que se prefieran las casas de cambio por encima de los bancos. De acuerdo con la revista Dinero (2013), las comisiones que ellas cobran por el envío, oscilan entre $3 \%$ y $5 \%$ del valor total de la operación, mientras que en el banco la comisión por el giro vale entre US\$20 y US\$30, dependiendo de la entidad y del país de origen. El monto máximo permitido que puede recibirse en casas de cambio es de US\$10.000 diarios, y si supera dicho cantidad, debe hacerse la operación a través de un banco. Si el monto recibido no excede el límite para declarar renta, el único impuesto cobrado es el de 4 x 1.000 al recibir el dinero en efectivo.

Bajo el periodo analizado y según el Banco de la República, en promedio el $72,1 \%$ de las remesas que ingresan a Colombia proviene de España y Estados Unidos, teniendo por separado una participación muy similar en los últimos nueve años (36 \% aproximadamente). En este mismo periodo, Venezuela ha venido ganado una importante participación, ya que los envíos han pasado de $0.3 \%$ al $13.1 \%$ en menos de una década, aunque en términos comparativos con los dos países de referencia, su contribución es aún discreta. El restante $15 \%$ proviene del Reino Unido, Italia, Ecuador, Holanda y, con un fuerte repunte en los últimos años, de Chile.

Desde el primer trimestre de 2005 al segundo de 2008, es decir antes de estallar la crisis financiera mundial, el crecimiento de las remesas enviadas desde España y Estados Unidos fueron positivas (superior al $3 \%$ en promedio para ambas), pero a partir de allí hasta la mitad del año 2013, existe un cambio total de la situación, pues se ha experimentado una contracción del $0.4 \%$ para las remesas enviadas desde Estados Unidos y del $1.3 \%$ para aquellas enviadas desde España, en promedio.

En efecto, para 2009, la desregulación económica, los altos precios de las materias primas (sobre todo del petróleo), la crisis alimentaria mundial y energética, así como una crisis crediticia, hipotecariay de confianza en los mercados, comenzaron a azotar a Norte-américa y luego a Europa. Siguiendo a Grande (2010), la crisis afectó de manera lesiva a Colombia y a Latinoamérica no solo en el envío de remesas, sino también en la migración: «Los migrantes fueron las primeras víctimas de la degradación de las condiciones económicas en los países desarrollados, lo cual afecto directamente al flujo de remesas constituyendo un factor decisivo en la transmisión de la crisis hacia América Latina». (Grande, 2010, p.2857)

Independientemente del país analizado, la crisis financiera mundial afectó de manera directa el envío de recursos financieros a nuestro país. De acuerdo con Argüello (2011, p.12), dichos envíos disminuyeron durante la mayor parte de 2009, presentándose la mayor caída en el mes de julio, cuando su valor se derrumbó en $23 \%$, y para todo el 2009 fue de $14,4 \%$. La IED se desplomó en $21 \%$ para el primer trimestre, y ya para el cuarto, sufrió una caída del $64.6 \%$. 
Lo anterior ha condicionado el comportamiento de corto, medio y largo plazo de las remesas enviadas desde España y Estados Unidos, ya que ha sido expansivo y luego recesivo bajo el periodo analizado, comportamiento que ha estado al tenor de la situación económica mundial y de su producto interno bruto. Debido a que la mayoría de las remesas se envía desde España, la crisis por la que ha atravesado este país, ha afectado de forma directa a muchos de los residentes que se benefician de estos dineros. La Figura 3 manifiesta que el PIB español guarda una fuerte relación con el envío de remesas a nuestro país, y muestra una tendencia a la baja para ambos rubros a partir del año 2008, fecha en donde se acentúa la crisis financiera. Un análisis de correlación simple muestra que su valor asciende a 0,72 , lo cual evidencia no solo el comportamiento al mismo compás de ambos rubros sino que su relación es pro cíclica, por tanto, los auges en el nivel de actividad económica impulsan el envío de dinero y viceversa.

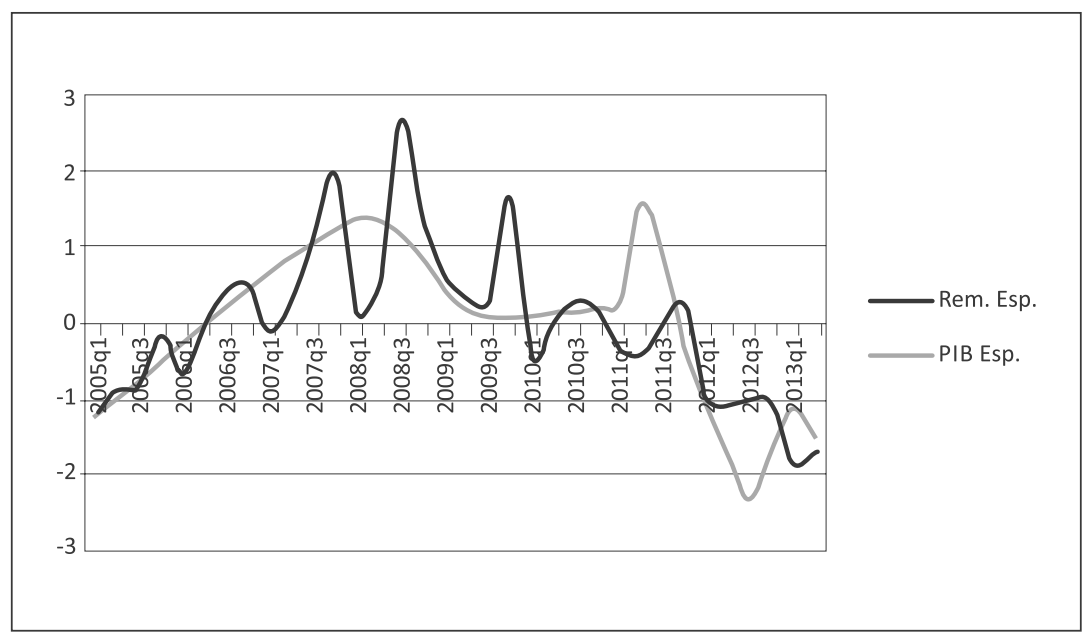

Figura 3. Evolución del PIB y las remesas de España normalizados. 2005:1 - 2013:2. Millones de USD (2005=100).

Fuente: elaboración de los autores con datos Banco de la República. Rem. Esp.: Remesas España. PIB Esp.: PIB España

Finalmente, según las cifras del Ministerio de Empleo y Seguridad Social del Gobierno de España, el número de colombianos en ese país a inicios del 2010 alcanzaba los 284,000 , pero por causa de los elevados índices de desempleo (más de 20 puntos porcentuales), el éxodo de nacionales se estima en alrededor 
de 20,000 personas en los últimos tres años. La región más afectada con la inmigración ha sido el Eje Cafetero, ya que de ellos, el $67 \%$ pertenece a ella.

Para el caso de Estados Unidos, la situación es similar al inicio del periodo analizado, aunque como se nota, el envío después del inicio de la crisis fue mucho más bajo comparado con España, pero al final se ha estabilizado un poco más que el del país europeo. La Figura 5 muestra que desde 2005 hasta 2008, el PIB norteamericano crece al igual que las remesas, pero una vez iniciada la fase recesiva, los envíos de dinero a Colombia también sufren una fuerte caída, pero a diferencia de España, el PIB norteamericano se recupera y las remesas de nuevo se activan, ya para 2013 vuele a tener los niveles mostrados en el 2006. La correlación antes de la crisis es 0,77 ; en la crisis alcanza 0,68 y finalmente después de ella es del 0,31; es decir, todas son elevadas y procíclicas.

La razón de tal comportamiento estriba en que las condiciones laborales, a pesar de la crisis en Estados Unidos, son mejores y existen posibilidades de ascenso. Además, el desempleo es mucho más bajo que en Europa, pues entre 2010 y 2012 pasó del $9.6 \%$ al $7.6 \%$, mientras que en España para los mismos años pasó de $20.5 \%$ a $26.3 \%$. Por tales razones muchos colombianos han optado por quedarse en Estados Unidos o migrar desde España hacia este país.

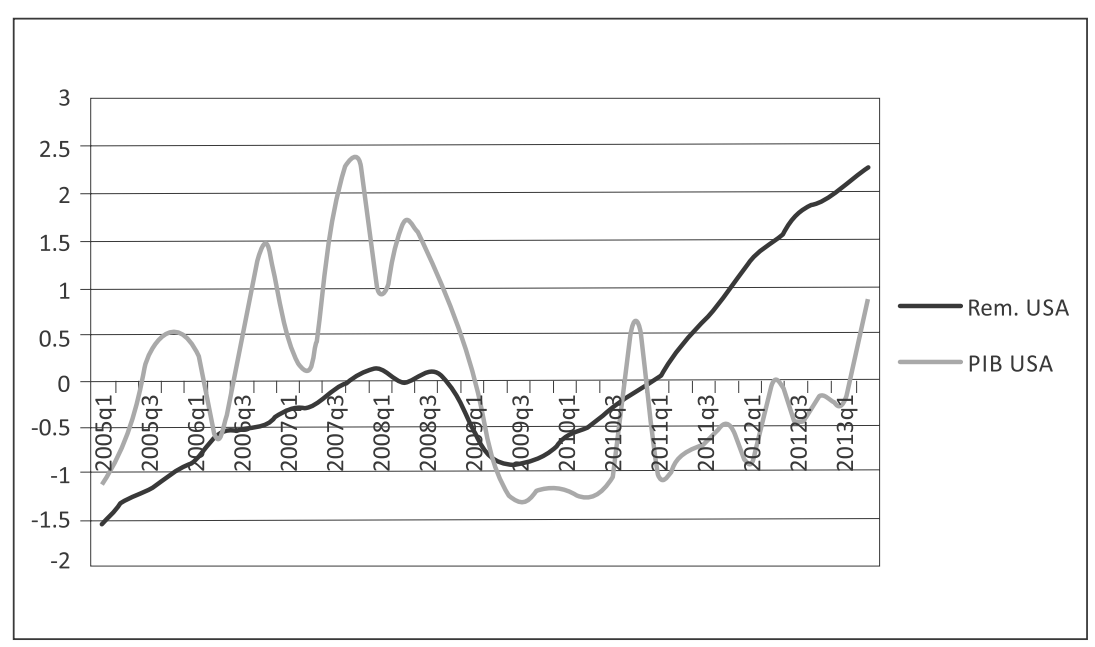

Figura 4. Evolución del PIB y las remesas de España normalizados. 2005:1 - 2013:2. Millones de USD (2005=100).

Fuente: elaboración de los autores con datos Banco de la República. 
De acuerdo con el BID (2007), en nuestro país, básicamente, las remesas son utilizadas para gastos recurrentes, es decir para solventar las necesidades básicas de las familias, tales como alimentos, vestuario, vivienda (pago de arriendo o cuota de crédito), salud y otros con porcentajes más bajos tales como gastos de inversión, bienes de consumo durable y ahorro. Efectivamente, el estudio muestra que los destinos de las remesas son para alimentación (29.3\%), servicios públicos $(23.3 \%)$; vivienda (15.5\%), salud (6.2\%), educación (5.8 $\%)$, transporte (5.4\%), vestuario (3.9\%), otros $(10.6 \%)$. Frente a esta destinación, el estudio recalca lo siguiente:

El tema de estudio de las remesas ha despertado un especial interés en las autoridades colombianas de buscar alternativas que permitan reorientar parte de estos recursos hacia sectores productivos de la economía. Sin embargo, son los beneficiarios quienes deciden su utilización y mientras las condiciones internas con respecto al empleo e ingreso no sean favorables, los beneficiarios no tendrán incentivos para incrementar su demanda en bienes durables, inversión y ahorro. (BID, 2007, p.36)

La caracterización de los receptores o beneficiarios de las remesas en nuestro país, siguiendo el estudio del BID (2007, p. 34), son jefes de hogar (60\%) quienes, en su mayoría, son mujeres cuya edad promedio oscila en 40 años. Sus niveles de educación son menores al de sus familiares en el exterior. Así las cosas, el $40 \%$ presenta un nivel de educación inferior a la secundaría, el $31 \%$ tiene bachillerato completo y el $28 \%$ estudios superiores. El $40 \%$ de los receptores tiene empleo, mientras que de los emisores el $99.3 \%$ cumple con esta condición. Las restantes actividades de los beneficiarios son al hogar $(35.6 \%)$ y a estudiar tan solo el $12.9 \%$. Los principales receptores de remesas se ubican en la región del Pacífico (32\%), Eje Cafetero (19\%), Antioquia (16\%), Bogotá (16\%), Atlántico (10\%) y finalmente los Llanos Orientales (4\%). De otro lado, según el estudio realizado por Garay y Rodríguez (2005, p.32), los receptores de remesas en casas de cambio son mayoritariamente mujeres $(76 \%)$, la edad promedio de los receptores es 40 años, siendo el 11,1 $\%$ mayor de 60 años. El 50,8 \% recibe remesas de familiares en primer grado de consanguinidad (hermanos, hijos y padres), el 15,7\% de su cónyuge o compañero y otro $15 \%$ de personas con quienes no tiene parentesco. El $93 \%$ de los remitentes de remesas es colombiano o hijo de padres colombianos.

Según García (2010), las remesas están ligadas al comportamiento de las migraciones de colombianos, más como un resultado que como una causa del fenómeno. Para corroborar sus ideas, se sumaron el número de emigrantes hacia los dos países de referencia, al igual que el monto de remesas enviadas a nuestro país en el periodo analizado.

Los resultados mostraron, por lo menos gráfica y estadísticamente hablando, que 
la relación a largo plazo entre las remesas y el número total de emigrantes de España y Estados Unidos es moderadamente alta, toda vez que las correlaciones a nivel tanto contemporáneo como rezagado superan el valor de 0,62 .

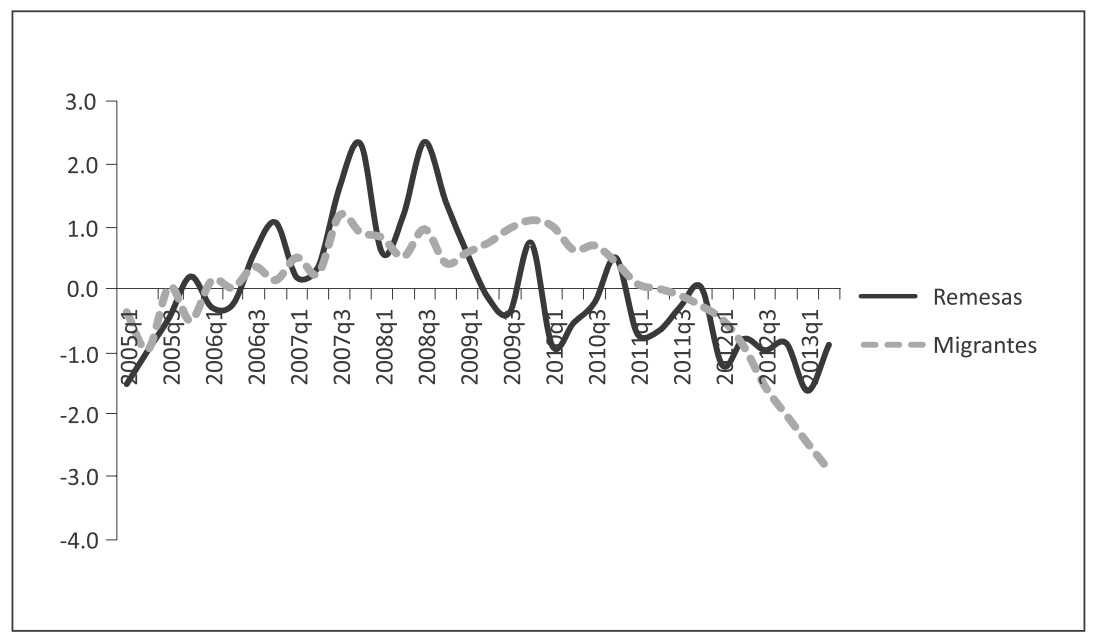

Figura 5. Relación contemporánea estandarizada trimestral entre los emigrantes y las remesas. España y Estados Unidos. 2005:01-2013:2. Millones de USD (2005=100)

Fuente: cálculos propios. Banco de la República, Ministerio de Empleo y Seguridad Social del Gobierno de España, y Pew Hispanic Research Center.

Lo anterior podría indicar que las remesas se envían en el mismo periodo (trimestre) en que el migrante llega al país de destino, pero, en otros casos, son enviadas en el periodo posterior, lo cual genera indicios de que las personas deben tener un margen de adaptación ya sea por búsqueda de empleo o por obtener sus primeros ingresos, para posteriormente enviar dinero a sus familias en Colombia.
Otro resultado que vale la pena destacar es que dicha correlación es positiva, lo que indicaría que altas olas de migraciones conllevan altos envíos de remesas, ya sea en el mismo periodo en que surge la migración o después, y viceversa. Es decir, bajas migraciones implican menores envíos de dinero a Colombia ${ }^{3}$.

$3 \quad$ La Figura 4 se presenta de forma estandarizada o normalizada para poder apreciar los comportamientos de las dos variables de manera conjunta, ya que de otra forma por los valores tan dispares que asumen ellas, el gráfico no se entendería. 


\section{Modelos econométricos para España y Estados Unidos ${ }^{4}$}

De acuerdo con lo establecido por García (2010), Montoya et al. (2010), Castillo (2001), Roca (2009) y Lozano (2008), el envío de remesas está determinado por el PIB tanto nacional como del país de donde provienen los envíos, del tipo de cambio entre los países, de los niveles de desempleo y finalmente del número de emigrantes.

Las series temporales de las remesas fueron extraídas del Banco de la República, de forma trimestral desde 2005:1 a 2013:2 y llevadas a precios constantes de 2005 a través del IPC local. Para obtener el tipo de cambio real, tanto para el dólar como para el euro, se multiplicó el tipo de cambio nominal de las divisas por los IPC relativos del país receptor y del emisor. En el caso de la tasa de desempleo elegida, es la presentada para las 24 ciudades más importantes de Colombia conforme al DANE, porque es a estas adonde llega la mayor cantidad de remesas enviadas desde el exterior.

Las series para el PIB e IPC de Estados Unidos y España a precios constantes de 2005 fueron extraídas del Fondo Monetario Internacional. Finalmente, el número de emigrantes se obtuvo del Ministerio de Empleo y Seguridad Social para el caso de España, y del Pew Hispanic Research Center, para los Estados Unidos ${ }^{5}$.

En este orden de ideas, el modelo para Estados Unidos es el siguiente:

$$
\begin{aligned}
& \text { LREMUSA }_{t}=\beta_{1}+\beta_{2} \text { LPIBC }_{t}+\beta_{3} \text { LPIBUSA }_{t}+\beta_{4} \text { LTCPD }_{t} \\
& +\beta_{5} \text { LMIGUSA }_{t}+\beta_{6} \text { LDES }_{t}+\omega_{t}
\end{aligned}
$$

Donde LREMUSA son las remesas enviadas a Colombia desde Estados Unidos, LPIBC es el PIB de Colombia, LPIBUSA el PIB de EE.UU., LTCPD denota el tipo de cambio real peso-dólar, LMIGUSA son emigrantes colombianos a
EE.UU., y LDES recoge el desempleo en Colombia. Finalmente, $\omega_{t}$ es una variable aleatoria que se supone cumple con los supuestos estadísticos clásicos, y que recoge la influencia de otras variables que no han sido tenidas en cuenta al

$4 \quad$ Los siguientes modelos no están basados en una teoría general que explique el envío de remesas porque dicha teoría aún no se construye. En este orden de ideas, se intenta capturar básicamente su comportamiento desde la teoría macroeconómica y la observación empírica. Debe recordarse en este sentido que los modelos econométricos también pueden ser construidos desde hipótesis de comportamiento y no necesariamente desde teorías, como lo manifiestan en sus páginas iniciales los textos guías clásicos como Greene (2002, p.1) o Gujarati y Porter (2000, p. 3 у 9$)$.

5 Como se mencionó anteriormente existen diversos factores que explican el envío de remesas al igual que los fenómenos migratorios, los cuales desbordan la frontera de la economía. Por tanto, el modelo econométrico intenta capturar los fenómenos macroeconómicos relevantes que posiblemente explican el fenómeno, incluyendo la cuantía de migrantes como variable social. Otras variables de otras áreas del conocimiento quedan por fuera del alcance del mismo, no solo por falta de información, sino porque como lo reconocen Garay y Rodríguez (2005), es un fenómeno que aún está por ser abordado de manera interdisciplinar. 
momento de explicar el envío de remesas desde Estados Unidos a nuestro país. Cabe resaltar que todas las variables están expresadas en logaritmos, por tanto los parámetros se deben entender como elasticidades.

Ahora, el modelo para España es el siguiente:

$$
\begin{aligned}
& L R E M E_{t}=\beta_{1}+\beta_{2} L P I B C_{t}+\beta_{3} L P I B E_{t}+\beta_{4} L T C P E_{t} \\
& +\beta_{5} L M I G E_{t}+\beta_{6} L D E S_{t}+\varepsilon_{t}
\end{aligned}
$$

Donde LREME son las remesas enviadas a Colombia desde España, LPIBC es el PIB de Colombia, LPIBE el PIB español, LTCPE denota el tipo de cambio real peso-euro, LMIGE son emigrantes colombianos a España, y LDES recoge el desempleo en Colombia. Finalmente, $\varepsilon_{\mathrm{t}}$ es una variable aleatoria que se supone cumple con los supuestos estadísticos clásicos, y que recoge la influencia de otras variables que no han sido tenidas en cuenta al momento de explicar el envío de remesas desde España a Colombia. Vale la pena anotar que al igual que en el modelo anterior, todas las variables están expresadas en logaritmos, de tal forma que los parámetros se deben también entender como elasticidades ${ }^{6}$.

Lo que se espera de las variables analizadas independientemente del país que provengan, es que la relación entre las remesas y el PIB colombiano sea negativa, ya que si las cosas marchan bien a nivel de agregado en la economía colombiana, los extranjeros enviarán una menor cantidad de dinero, y viceversa, es decir que recesiones económicas internas amplían el flujo enviado de dinero del exterior. Frente al PIB del país desde donde se envían los giros, se supone que la relación es positiva, toda vez que si la actividad económica es buena afuera, hay más dinero para enviar remesas a nuestro país.

Siguiendo a Castillo (2001), con el tipo de cambio real, la relación no es tan clara, pues se puede decir que si hay una devaluación del peso frente a la divisa, no necesita enviarse una cantidad muy grande de dinero desde fuera, ya que una menor cantidad compra la misma canasta de consumo en nuestro país. Pero, por otra parte, podría percibirse la devaluación también como una excelente oportunidad de enviar más remesas para obtener un mayor «ingreso real» en los giros. Así que el signo esperado puede ser positivo o negativo. Respecto a los emigrantes,

\footnotetext{
La relación intertemporal entre las variables no debe descartarse, sobre todo porque de las enlistadas anteriormente hay algunas de carácter estructural como el PIB, y otras más volátiles como el tipo de cambio. Así por ejemplo, para esta última podría suceder que los agentes tengan en cuenta su comportamiento en el trimestre anterior cuando desean enviar las remesas hoy. Atendiendo a esta anotación se explorarán formas funcionales contemporáneas y no contemporáneas.
} 
se espera una relación positiva, pues si es mayor el número de personas que abandonan el país, las remesas deberán ser más altas. Finalmente, si el desempleo colombiano se dispara, se esperaría que las remesas aumenten, ya sea por los residentes o por nuevos emigrantes colombianos en el exterior, expulsados por las condiciones laborales de nuestro país. Antes de estimar los modelos, es necesario establecer si las series están cointegradas o no, con el objetivo de no caer en el problema de regresiones espurias.

\section{Análisis de cointegración}

Para indagar por el orden de integración de las series en mención, se implementó la prueba Dickey-Fuller aumentada (DFA). La prueba DFA, permite identificar si existen raíces unitarias, es decir, decide si la serie es o no estacionaria, observando siempre el cumplimiento de supuestos, para luego pasar a determinar el rango de cointegración del sistema, esto es, aplicar prueba de cointegración de Johansen. Debe mencionarse que si dos variables están integradas en diferentes órdenes, no habrá cointegración. Los resultados fueron los siguientes ${ }^{7}$ :

Tabla 1. Órdenes de integración. Dickey Fuller.

\begin{tabular}{|l|c|c|c|c|c|}
\hline EE.UU. & Niveles & Primera Diferencia & España & Niveles & Primera \\
\hline Variable & ADF & ADF & Variable & ADF & ADF \\
\hline LREMUSA & $(-2.557)$ & $(-6.519)^{*}$ & LREME & $(-0.269)$ & $(-6.267)^{*}$ \\
LPIBC & $(-1.039)$ & $(-4.892)^{*}$ & LPIBC & $(-1.039)$ & $(-4.892)^{*}$ \\
LPIBUSA & $(-0.060)$ & $(-2.957)^{* *}$ & LPIBE & $(-1.724)$ & $(-3.684)^{* *}$ \\
LTCPD & $(-2.407)$ & $(-5.502)^{*}$ & LTCPE & $(-1.439)$ & $(-5.549)^{*}$ \\
LMIGUSA & $(-1.005)$ & $(-7.178)^{*}$ & LMIGE & $(-0.618)$ & $(-5.235)^{*}$ \\
LDES & $(-1.183)$ & $(-3.033)^{* *}$ & LDES & $(-1.183)$ & $(-3.033)^{* *}$ \\
\hline
\end{tabular}

Fuente: elaboración de los autores.

Nota: ** Rechaza la hipótesis nula de un proceso con raíz unitaria al $5 \%$.

*** Rechaza la hipótesis nula de un proceso con raíz unitaria al $1 \%$.

La prueba muestra que las series en niveles, tanto para Estados Unidos como para España, presentan raíces unitarias para todas las series analizadas, es decir, son caminatas aleatorias. En primeras diferencias, todas las series se transforman en estacionarias y por tanto se concluye que son integradas de orden uno, o I(1). Lo anterior indica que se puede implementar un análisis de cointegración, toda vez que las series presentan el mismo grado de integración. Para tal efecto se utilizará el test de Johansen.

$\overline{7} \quad$ Los resultados ampliados para ambos países se relacionan en los anexos 1 y 2. 
Dinámica económica de las remesas enviadas desde España y Estados Unidos a Colombia ... Andrés Mauricio Gómez Sánchez - Zoraida Ramírez Gutiérrez

Tabla 2. Test de cointegración de Johansen (traza). Estados Unidos.

\begin{tabular}{|l|c|c|c|c|}
\hline $\begin{array}{l}\text { Hypothesized } \\
\text { No. of CE(s) }\end{array}$ & Eigenvalue & $\begin{array}{c}\text { Trace } \\
\text { Statistic }\end{array}$ & $\begin{array}{c}\mathbf{0 , 0 5} \\
\text { Critical Value }\end{array}$ & Prob.** \\
\hline None $*$ & 0,903 & 186,164 & 95,754 & 0,000 \\
At most 1* & 0,863 & 113,899 & 69,819 & 0,000 \\
At most 2* & 0,524 & 52,369 & 47,856 & 0,018 \\
At most 3 & 0,446 & 29,342 & 29,797 & 0,056 \\
At most 4 & 0,275 & 11,025 & 15,495 & 0,210 \\
At most 5 & 0,033 & 1,046 & 3,841 & 0,306 \\
\hline
\end{tabular}

Fuente: elaboración de los autores.

Tabla 3. Test de cointegración de Jhoansen (traza). España.

\begin{tabular}{|l|c|c|c|c|}
\hline $\begin{array}{l}\text { Hypothesized } \\
\text { No. of CE(s) }\end{array}$ & Eigenvalue & $\begin{array}{c}\text { Trace } \\
\text { Statistic }\end{array}$ & $\begin{array}{c}\mathbf{0 , 0 5} \\
\text { Critical Value }\end{array}$ & Prob.** \\
\hline None $*$ & 0,892 & 184,441 & 95,754 & 0,000 \\
At most 1* & 0,775 & 115,321 & 69,819 & 0,000 \\
At most 2* & 0,674 & 69,100 & 47,856 & 0,000 \\
At most 3* & 0,498 & 34,371 & 29,797 & 0,014 \\
At most 4 & 0,330 & 13,008 & 15,495 & 0,115 \\
At most 5 & 0,019 & 0,593 & 3,841 & 0,441 \\
\hline
\end{tabular}

Fuente: elaboración de los autores.

En la Tabla 2 se muestra que existen al menos dos vectores de cointegración para el caso de los Estados Unidos, y en la Tabla 3, que existen al menos tres vectores para España. Esto permite asegurar que los modelos cointegrantes planteados en las ecuaciones 1 y 2 no son espurios o falsos, es decir, siguiendo a Greene (2002, p.632) las series por separado son aleatorias, pero de manera conjunta forman una combinación lineal estacionaria, que permite darle solidez a la relación a largo plazo entre las variables consideradas. De esta manera, los modelos se pueden estimar sin ninguna dificultad estadística. Los resultados se relacionan a continuación ${ }^{8}$ :

$8 \quad$ Los resultados ampliados para ambos países se relacionan en los anexos 5 y 6 . 
Apuntes Cenes Vol. 33, No. 58, ISSN 0120-3053

Julio - Diciembre 2014, Págs. 45-82

Tabla 4. Estimación del modelo para Estados Unidos

\begin{tabular}{|c|c|c|c|}
\hline Variable & Coeficiente & Desv. Estandar & P-valor \\
\hline C & $-1,000$ & 3,798 & 0,794 \\
LPIBE & 0,760 & 0,399 & 0,062 \\
LMIGE & 0,911 & 0,101 & 0,000 \\
LDES & $-1,023$ & 0,110 & 0,000 \\
LPIBC & $-1,037$ & 0,136 & 0,000 \\
LTCPE & 0,526 & 0,128 & 0,000 \\
R2 & 0,886 & P-Valor F & 0,000 \\
\hline
\end{tabular}

Fuente: elaboración de los autores. Estimaciones bajo consistencia Newey-West.

En el caso norteamericano, el modelo presenta un buen ajuste a nivel individual $\mathrm{y}$ agregado, toda vez que los p-valores son todos cercanos a cero y $\mathrm{R}^{2}$ es elevado $(65,9 \%)$, y el p-valor del estadístico F es cero. La variable tipo de cambio real entre el peso y el dólar, no cumple con dicha significancia individual y por tanto no es relevante para el modelo. Frente a los signos esperados, todos son los correctos.

En términos particulares, las remesas enviadas y el PIB norteamericano guardan una relación altamente sensible, toda vez que la elasticidad es igual a 4.4; por tanto, bajo condiciones ceteris paribus, incrementos en el nivel de actividad económica estadounidense incentivan el envío de más giros a Colombia. En otras palabras, si el PIB de Estados Unidos se eleva en $1 \%$, el monto enviado de remesas se amplía en 4,4\% para el periodo muestral analizado, dejando todo lo demás constante. Posiblemente esto obedezca a que los residentes colombianos se han podido emplear más fácilmente a pesar de la recesión, como lo muestran las cifras macroeconómicas del mercado laboral de dicho país.

Frente al número de emigrantes que viajan a EE.UU., existe una relación positiva e inelástica con las remesas (0.7 aproximadamente), dejando 1o demás constante. Así, los incrementos en el número de colombianos que viajan a EE.UU., permite que se eleven las remesas en la actualidad, pero en una menor proporción. En el caso del desempleo, si en nuestro país, este aumenta en $1 \%$, las remesas enviadas aumentan en $0.39 \%$, dejando lo demás constante. Finalmente, con el PIB nacional, la relación de las remesas es elástica, es decir, sensible pero baja (-1.2), ceteris paribus. Así, incrementos en el PIB colombiano del $1 \%$, impulsan a que las remesas se reduzcan hoy en una proporción un poco más baja.

Para el tipo de cambio real entre el peso y el dólar, los resultados muestran que si hay una devaluación del peso, se envían más remesas para obtener 
un mayor «ingreso real» en los giros. En este orden de ideas, la relación es directa y además inelástica ceteris paribus, por lo que si la devaluación del peso frente al euro se incrementa en 1 $\%$, las remesas enviadas desde España aumentan en $0.18 \%$. Los problemas de heterocedasticidad y autocorrelación no afectan la consistencia de los parámetros, ya que fueron estimados bajo la corrección de Newey-West (HAC). Adicionalmente, la multicolinealidad es muy baja entre los regresores, siendo la más elevada la que existe entre el desempleo y el PIB colombiano, aunque tan solo fue del 0,4 siguiendo una matriz de correlaciones simples no mostrada aquí. Finalmente, los residuales estimados para $\omega_{t}$ son estacionarios de acuerdo con la prueba $\mathrm{ADF}$, aunque de nuevo este resultado no debe causar sorpresa, pues las series de este modelo están cointegradas con el mismo orden?.

En el caso de España, se encuentra que el ajuste individual es bueno ya que los p-valores de los regresores son cercanos al cero y el nivel de significancia conjunto es alto de acuerdo con el $\mathrm{R}^{2} \mathrm{y}$ al p-valor del estadístico F. El intercepto no cumple con lo anterior, pero se mantiene para garantizar que los residuales sean minimizados. El parámetro del PIB español es significativo también, pero al 6,2\% de acuerdo con su p-valor ${ }^{10}$. Frente a los signos esperados, todos son correctos.

Tabla 5. Estimación del modelo para España

\begin{tabular}{|c|c|c|c|}
\hline Variable & Coeficiente & Desv. Estandar & P-valor \\
\hline C & $-1,000$ & 3,798 & 0,794 \\
LPIBE & 0,760 & 0,399 & 0,062 \\
LMIGE & 0,911 & 0,101 & 0,000 \\
LDES & 1,023 & 0,110 & 0,000 \\
LPIBC & $-1,037$ & 0,136 & 0,000 \\
LTCPE & 0,526 & 0,128 & 0,000 \\
R2 & 0,886 & P-Valor F & 0,000 \\
\hline
\end{tabular}

Fuente: elaboración de los autores. Estimaciones bajo consistencia Newey-West.

$\overline{9} \quad$ La prueba ADF muestra un estadístico de prueba igual a (-4.81), con un p-valor de (0.00). (Ver anexo 7).

10 Debe recordarse que la significancia estadística es elegida de manera apriorística por parte del investigador, la cual generalmente se ubica entre $1 \%$ y máximo $10 \%$. El p-valor indica el máximo valor probabilístico al que puede aceptarse la hipótesis nula de no significancia estadística. Como se muestra en la Tabla 5, para la variable PIB de España (LPIBE) su p-valor es igual al 6,2 \%, indicando que la probabilidad de equivocación al momento de considerar dicha variable como relevante para el modelo es baja, pues aún no alcanza el $10 \%$. Por tanto, la variable debe considerarse como relevante y estadísticamente significativa. 
La salida evidencia que con el PIB español, la relación es inelástica $(0.76)$ y positiva, lo que muestra que efectivamente una mejora en el nivel de actividad económica español, permite enviar más remesas a Colombia, ceteris paribus, posiblemente como en el caso anterior porque los colombianos en dicho país tienen acceso a más y mejores fuentes de empleo.

Para los emigrantes existe una relación positiva e inelástica con las remesas, dejando lo demás constante. Así, si los incrementos en el número de colombianos que viajan a España es del $1 \%$, se incrementan las remesas en una menor proporción $(0.91 \%)$. Para el caso del desempleo, la relación es elástica unitaria, es decir la sensibilidad es intermedia. En otras palabras, si el desempleo se incrementa en $1 \%$, el incremento de las remesas será del mismo orden, dejando todo lo demás constante. De otro lado, las remesas enviadas desde España en el periodo muestral se comportan de forma elástica unitaria frente al PIB nacional y de manera inversa, manteniendo lo demás constante. Es decir, que incrementos en el PIB nacional del $1 \%$ ocasiona que las remesas se reduzcan hoy en una proporción igual (1\%).

También como en el caso de Estados Unidos, en lo relacionado con el tipo de cambio real entre el peso y el euro, los resultados refuerzan la hipótesis de que si hay una devaluación del peso frente a la divisa, existe una excelente oportunidad de enviar más remesas para obtener un mayor «ingreso real» en los giros. En este orden de ideas, la relación es directa y además inelástica, por lo que si la devaluación del peso frente al euro se incrementa en $1 \%$, las remesas enviadas desde España aumentan en $0.5 \%$, dejando todo lo demás constante.

Igual que en el caso anterior, los parámetros fueron estimados bajo la corrección de Newey-West (HAC), por lo que su consistencia se mantiene ante los posibles problemas de heterocedasticidad y autocorrelación. Adicionalmente, la multicolinealidad también es muy baja entre los regresores, siendo de nuevo la más elevada la existente entre el desempleo y el PIB colombiano, aunque tan solo fue del 0,44 a partir de una matriz de correlaciones simples, no mostrada aquí. Finalmente, los residuales estimados para $\varepsilon_{\mathrm{t}}$ son estacionarios de acuerdo con la prueba $\mathrm{ADF}^{11}$.

\section{Mecanismo de corrección de errores (MCE)}

En el anterior acápite se mostró que existe una relación estable a largo plazo entre las remesas y las variables que las determinan, bajo dos escenarios, pero es muy probable que a corto plazo puedan surgir desequilibrios entre ellas. Por tal motivo se implementa un mecanismo de corrección de errores

$\overline{11}$ La prueba ADF muestra un estadístico de prueba igual a (-6.14), con un p-valor de (0.00). (Ver anexo 8). 
(MCE), apelando a Engle y Granger (1987), más específicamente al teorema de representación de Granger, el cual dice que si dos o más variables están cointegradas, entonces la relación se puede expresar como un MCE. Se estima a continuación un modelo de este tipo para cada país que trata de develar qué tan rápido o qué tan lento es el ajuste a la tendencia estable a largo plazo, los desequilibrios presentados a corto plazo.

El modelo MCE para Estados Unidos es el siguiente:

$$
\begin{aligned}
& \text { ALREMUSA } A_{t}=\alpha_{1}+\alpha_{2} \Delta L P I B C_{t}+\alpha_{3} \Delta L P I B U S A_{t}+\alpha_{4} \Delta L T C P D_{t} \\
& +\alpha_{5} \Delta L M I G U S A_{t}+\alpha_{6} \Delta L D E S_{t}+\alpha_{7} \omega_{t-1}^{\wedge}+\delta_{t}
\end{aligned}
$$

Donde $\Delta$ es la primera diferencia de la variable, $\widehat{\omega}_{t-1}$ son los residuales del modelo cointegrante (ecuación 1) rezagados en un periodo, y $\delta_{t}$ denota los errores estocásticos que se supone están bien comportados. El parámetro $\alpha_{7} \mathrm{se}$ conoce como el coeficiente de error de equilibrio, el cual muestra la discrepancia del ajuste entre el corto y el largo plazo, en este caso de las remesas ${ }^{12}$. Los resultados se muestran a continuación ${ }^{13}$ :

Tabla 6. Método de corrección de errores (MCE) para Estados Unidos.

\begin{tabular}{|l|c|c|}
\hline \multicolumn{1}{|c|}{$\begin{array}{c}\text { Variable: D } \\
\text { (LREMUSA) }\end{array}$} & Coeficiente & P-Valor \\
\hline C & $-0,016$ & 0,335 \\
D(LPIBUSA) & $-0,500$ & 0,771 \\
D(LMIGUSA) & 0,539 & 0,000 \\
D(LDES) & $-0,345$ & 0,000 \\
D(LPIBC) & 2,186 & 0,059 \\
D(LTCPD) & 0,214 & 0,243 \\
RES(-1) & $-0,813$ & 0,000 \\
R2 & 0,660 & \\
DW & 1,543 & \\
P-valor F & 0,000 & \\
\hline
\end{tabular}

Fuente: elaboración de los autores. Estimaciones bajo Newey-West. Donde D es igual la primera diferencia $\Delta_{\text {y }} \operatorname{RES}(-1)$ a $\widehat{\omega}_{t-1}$.

\footnotetext{
12 Debe tenerse en cuenta que el coeficiente de error de equilibrio debe cumplir con que sea menor que uno en términos absolutos, significativo de manera estadística y negativo.

13 Los resultados ampliados para ambos países se relacionan en el anexo 9.
} 
La estimación revela que el coeficiente de error de equilibrio es diferente de cero (-0.813), y estadísticamente significativo, por tanto el modelo no está en equilibrio a corto plazo. En este orden de ideas, la variable muestra que el $81,3 \%$ de la discrepancia entre la relación de las remesas y las variables explicativas a corto y a largo plazo, se elimina al siguiente trimestre. En otras palabras, si la variación de las remesas está por arriba (debajo) de su valor de equilibrio, a largo plazo comenzará a disminuir (aumentar) lentamente en el trimestre a fin de corregir la brecha.

En el caso español, el MCE es:

$$
\begin{aligned}
& \triangle L R E M E_{t}=\gamma_{1}+\gamma_{2} \Delta L P I B C_{t}+\gamma_{3} \Delta L P I B E_{t}+\gamma_{4} \Delta L T C P D_{t} \\
& +\gamma_{5} \Delta L M I G E_{t}+\gamma_{6} \Delta L D E S_{t}+\gamma_{7} \varepsilon_{t-1}^{\wedge}+\theta_{t}
\end{aligned}
$$

Donde $\Delta$ es la primera diferencia de la variable, $\varepsilon_{t-1}$ son los residuales del modelo cointegrante (ecuación 2) rezagados en un periodo, y $\theta_{t}$ denota los errores estocásticos que se supone están bien comportados. Como en el caso anterior, el parámetro $\gamma_{7}$ es el coeficiente de error de equilibrio, el cual muestra la discrepancia del ajuste ente el corto y el largo plazo de las remesas. ${ }^{14}$

Al igual que para Estados Unidos, la estimación revela que el coeficiente de error de equilibrio es diferente de cero (-0.917) y estadísticamente significativo, por tanto el modelo tampoco está en equilibrio a corto plazo. Así, la variable muestra que el $91,7 \%$ de la divergencia entre la relación de las remesas y las variables explicativas a corto y a largo plazo, se elimina al siguiente trimestre. Visto de otra manera, si la variación de las remesas está por arriba (debajo) de su valor de equilibrio, a largo plazo comenzará a disminuir (aumentar) lentamente en el trimestre a fin de corregir la discrepancia.

$\overline{14}$ Los resultados ampliados para ambos países se relacionan en el anexo 10. 
Dinámica económica de las remesas enviadas desde España y Estados Unidos a Colombia ... Andrés Mauricio Gómez Sánchez - Zoraida Ramírez Gutiérrez

Tabla 7. Método de corrección de errores (MCE) para España.

\begin{tabular}{|l|c|c|}
\hline $\begin{array}{c}\text { Variable: D } \\
\text { (LREMUSA) }\end{array}$ & Coeficiente & P-Valor \\
\hline C & 0,009 & 0,727 \\
D(LPIBE) & 0,664 & 0,386 \\
D(LMIGE) & 0,769 & 0,002 \\
D(LDES) & $-0,977$ & 0,000 \\
D(LPIBC) & $-1,769$ & 0,353 \\
D(LTCPE) & 0,570 & 0,005 \\
RES(-1) & $-0,917$ & 0,000 \\
R2 & 0,810 & \\
DW & 1,938 & \\
P-valor F & 0,000 & \\
\hline
\end{tabular}

Fuente: cálculos propios. Estimaciones bajo Newey-West. Donde D es igual la primera diferencia y $\operatorname{RES}(-1)$ a $\varepsilon_{t-1}$.

\section{CONCLUSIONES}

La recepción de remesas en nuestro país, a pesar de haber sufrido un fuerte desplome en los últimos años, ocasionado por la crisis económica financiera estadounidense y últimamente por la recesión económica española, aún sigue siendo un rubro importante en el PIB (1.7 $\%$ en promedio anual desde 2006) y en la balanza de pagos. Muchos hogares, sobre todo los pertenecientes a la AMCO y al suroccidente del país, aún tienen en las remesas el ingreso básico de subsistencia. En los dos últimos años, los envíos han sido crecientes desde Venezuela y más incisivamente desde Chile. Si esta tendencia continúa, deberán ser incluidos los envíos desde estos dos últimos países para futuros estudios.

Los modelos cointegrantes estimados muestran de manera comparativa que el flujo de remesas cuando mejora la economía internacional es mayor para Estados Unidos que para España, fenómeno que puede ser explicado sobre todo por los elevados niveles de desempleo español. En este orden de ideas, la hipótesis propuesta por Garay y Rodríguez (2005), se corrobora para este periodo de análisis. De otro lado, también se comprueba la planteada por García (2010), en cuanto a que las migraciones guardan una relación directa con el envío de remesas, pero se encuentra sorpresivamente en este estudio que la relación es poco sensible en ambos casos, sobre todo en el caso norteamericano, lo que puede indicar que no todos los emigrantes envían dinero a nuestro país.

La propuesta realizada desde este estudio, de que el desempleo nacional implica un mayor envió de remesas es comprobada también, 
pero los impactos son diferenciales, ya que es mayor para el caso español frente al norteamericano, lo cual también sorprende, pues la crisis fue y continua siendo muy fuerte en el país europeo.

Finalmente, existe evidencia frente al tipo de cambio, en el sentido de que se cumple una de las dos propuestas hechas por Castillo (2001) en ambos países emisores. En efecto, si hay una devaluación del peso frente al dólar (euro), los migrantes residentes en Estados Unidos (España) envían una mayor cantidad de dinero a nuestro país para aprovechar el incremento del poder adquisitivo del giro. Vale la pena destacar que la inelasticidad muestra que de alguna manera, el envío de remesas guarda cierta independencia de los comportamientos de los precios del dólar y del euro en el mercado nacional. Aunque para un país no considerado en este estudio, como Venezuela, el comportamiento del tipo de cambio es fundamental para lo que se ha denominado «el negocio de las remesas», ya que los diferenciales entre dólar-bolívar-peso originan prácticas de arbitraje, las cuales dejan ganancias nada despreciables a ambos lados de la frontera, situación con la cual muchas familias de ambos países obtienen sus ingresos mensuales. Esta situación ha conducido a que actualmente se fije un tipo de cambio exclusivo entre el bolívar y el peso para el envío de las remesas entre Colombia y Venezuela.

Las relaciones de causalidad entre las remesas y sus factores determinantes se presentan de forma contemporánea y no rezagada. En efecto, se probaron varias formas funcionales que presentaban rezagos entre las variables pero su robustez estadística fue muy pobre. Esto traduce que un trimestre es un tiempo suficiente para que quienes envían como quienes reciben dinero, evalúen la situación tanto económica como social de los países y tomen la decisión de enviar o recibir los giros.

Los resultados del test de Johansen tanto para España como para Estados Unidos, muestran que las series están cointegradas. Es decir, las variables que explican los envíos de las remesas referenciadas anteriormente hacen parte de un comportamiento estable a largo plazo, y no por una simple coincidencia tendencial. Dicha relación no presenta desviaciones extremadamente fuertes ni crecientes de forma ilimitada, por lo que existe una relación que no es espuria o falsa entre las variables incluidas. Adicionalmente, la relación es estacionaria, es decir, es una relación de equilibrio en el puro ámbito estadístico, por lo que los efectos de las perturbaciones o «shocks» son transitorios y no las desvían ampliamente de su estado, sobre todo para el caso norteamericano.

El MCE refuerza el resultado anterior, toda vez que evidencia que los desequilibrios a corto plazo en la relación con las variables consideradas, son pequeños y lentamente retoman la senda del largo plazo, aunque el caso norteamericano no es tan agudo como el español. Visto de otra forma, en el análisis del MCE 
para ambos escenarios se muestra una velocidad de convergencia entre el corto y largo plazo un poco diferente entre países, pero la integración ratifica la fuerza de la validez del modelo cointegrante a largo plazo. El comportamiento en las velocidades posiblemente obedezca a factores asociados con la crisis económica por la que han venido atravesando los países bajo análisis, pues esta ha sido mejor sorteada en el medio plazo por los estadounidenses que por los españoles.
Cabe resaltar finalmente que las relaciones causales mostradas en el modelo cointegrante en su mayoría son inelásticas o de elasticidad unitaria, lo que indica posiblemente que se envían las remesas desde España y Estados Unidos con algún grado de independencia de las condiciones económicas enlistadas aquí, por lo que deben pesar factores posiblemente de carácter familiar, afectivos o de urgencia económica que hacen enviar las remesas sin considerar de forma estricta fenómenos económicos o sociales.

\section{REFERENCIAS}

Arango, L., Montenegro, P. \& Obando, N. (2011). El desempleo en Pereira ¿sólo cuestión de remesas? Borradores de Economía, (636), 1-35.

Argüello, R. (2011). Efectos de la crisis internacional: remesas, comercio y respuesta de política en Colombia. Perfil de Coyuntura Económica, (17), 7-30.

Banco Interamericano de Desarrollo. (2007). Remesas internacionales en Colombia. Informe para Colombia. Bogotá: BID.

Castillo, R. (2001). Remesas: un análisis de cointegración para el caso de México. Frontera Norte, 13(26), 31-50.

Cerruti, M., \& Maguid, A. (2011, sept.). Remesas de los inmigrantes sudamericanos en España. En XI Jornadas Argentinas de Estudios de Población. Ciudad de Neuquén (p.1-22).

Engle, R. \& Granger, C. (1987). Co-integration and Error Correction: Representation, Estimation, and Testing. Econometrica, 55 (2), 251-76.

Faini, R. (2002, sept.). Migration, Remmitances and Growth. Documento de trabajo, Universidad de Brescia.

Garay, L. \& Rodríguez, A. (2005). La emigración internacional en Colombia: una visión panorámica a partir de la recepción de remesas. Bogotá: Ministerio de Relaciones Exteriores y la Organización Internacional para las Migraciones. 
García, R. (2010). Crisis financiera internacional, migración y remesas en América Latina. Ola Financiera, UNAM, 3(7), 120-147.

Grande, R. (2010). Remesas, crisis económica internacional y desarrollo en América Latina. En Congreso Internacional 1810-2010: 200 años de Iberoamérica (pp. 2849-2869).

Greene, W. (1999). Econometric Analysis. (Fifth Ed.). New Jersey: Prentince Hall.

Gujarati, D. \& Porter, D. (2009). Econometría. (5 ed.). México: Mc Graw Hill.

Hagen-Zanker, J. (2008). Why do people migrate? A review of the theoretical literature. Working Paper. Netherlands: Maastricht Graduate School of Governance. Maastricht University.

Lozano, F. (2008). Las remesas de los migrantes latinoamericanos y caribeños en los Estados Unidos. CEPAL Notas de Población, (86), 39-62.

Montoya, D., Restrepo, C., Arboleda, P., Ramírez, A. \& Viana, A. (2010). Remesas como instrumento de crecimiento económico en Colombia: remesas y el sector de la construcción en Colombia. Negocios Internacionales, 3(2), 64-86.

Mora, J. (2008). Relación entre la participación laboral y las remesas en Colombia. Borradores de Economía y Finanzas, (17), 1-25.

Mundell, R. (1957, junio). International Trade and Factor Mobility. American Economic Review, 47, 321-335). Adaptado por International Economics New York: MacMillan, 1968. p. 85-99.

Organización Internacional para las Migraciones (2005). Migración internacional, el impacto y las tendencias de las remesas en Colombia. (p. 1-136). En Memorias del Seminario. Bogotá.

Revista Dinero. (2013). Giros: ¿Sabe cómo recibirlos? Recuperado de: http://www.dinero. com/dinero-usted/edicion-impresa/articulo/giros-sabe-como-recibirlos/36384

Roa, M. (2011, enero-junio). Uso de las remesas procedentes de España en la región pacífica colombiana. Sociedad y Economía, (7), 45-80.

Roca, R. (2009). Las remesas y el tipo de cambio a corto plazo. Artículo libre. Perú: Universidad Nacional Mayor de San Marcos.

Romero, E., \& Salinas, D. (2010). La oferta laboral y el papel de las remesas internacionales: estudio de caso para la zona cafetera colombiana: Área Metropolitana Centro Occidente. Perfil de Coyuntura Económica, 15, 97-117.

Sinisterra, M. (2005). Migración laboral internacional, remesas y crecimiento económico. Estudios Gerenciales, 97, 83-100. 
Dinámica económica de las remesas enviadas desde España y Estados Unidos a Colombia ... Andrés Mauricio Gómez Sánchez - Zoraida Ramírez Gutiérrez

\section{Anexo 1. Test ADF para el caso Estados Unidos}

\begin{tabular}{|c|c|c|c|}
\hline \multicolumn{4}{|c|}{$\begin{array}{l}\text { Null Hypothesis: D(LTCPD) has a unit root } \\
\text { Exogenous: Constant } \\
\text { Lag Length: } 0 \text { (Automatic - based on SIC, maxlag=8) }\end{array}$} \\
\hline \multirow{2}{*}{\multicolumn{2}{|c|}{ Augmented Dickey-Fuller test statistic }} & t-Statistic & \multirow{5}{*}{$\begin{array}{l}\text { Prob.* } \\
\text { 7,40E-05 }\end{array}$} \\
\hline & & $-5,5020547$ & \\
\hline \multirow{3}{*}{ Test critical values: } & $1 \%$ level & $-3,6537297$ & \\
\hline & $5 \%$ level & $-2,9571102$ & \\
\hline & $10 \%$ level & $-2,6174337$ & \\
\hline \multicolumn{4}{|c|}{$\begin{array}{l}\text { Null Hypothesis: D(LMIGUSA) has a unit root } \\
\text { Exogenous: Constant } \\
\text { Lag Length: } 0 \text { (Automatic - based on SIC, maxlag=8) }\end{array}$} \\
\hline \multirow{2}{*}{\multicolumn{2}{|c|}{ Augmented Dickey-Fuller test statistic }} & t-Statistic & Prob.* \\
\hline & & $-7,178550011$ & $9,47 \mathrm{E}-07$ \\
\hline \multirow[t]{3}{*}{ Test critical values: } & $1 \%$ level & $-3,65372973$ & \\
\hline & $5 \%$ level & $-2,957110201$ & \\
\hline & $10 \%$ level & $-2,617433721$ & \\
\hline \multicolumn{4}{|c|}{$\begin{array}{l}\text { Null Hypothesis: D(LREMUSA) has a unit root } \\
\text { Exogenous: Constant } \\
\text { Lag Length: } 0 \text { (Automatic - based on SIC, maxlag=8) }\end{array}$} \\
\hline \multirow{2}{*}{\multicolumn{2}{|c|}{ Augmented Dickey-Fuller test statistic }} & t-Statistic & Prob.* \\
\hline & & $-6,519846682$ & $4,85 \mathrm{E}-06$ \\
\hline \multirow[t]{3}{*}{ Test critical values: } & $1 \%$ level & $-3,65372973$ & \\
\hline & $5 \%$ level & $-2,957110201$ & \\
\hline & $10 \%$ level & $-2,617433721$ & \\
\hline \multicolumn{4}{|c|}{$\begin{array}{l}\text { Null Hypothesis: D(LPIBUSA) has a unit root } \\
\text { Exogenous: Constant } \\
\text { Lag Length: } 0 \text { (Automatic - based on SIC, maxlag=8) }\end{array}$} \\
\hline \multirow{2}{*}{\multicolumn{2}{|c|}{ Augmented Dickey-Fuller test statistic }} & t-Statistic & Prob.* \\
\hline & & $-2,9570641$ & 0,041764624 \\
\hline Test critical values: & $1 \%$ level & $-3,65372973$ & \\
\hline & $5 \%$ level & $-2,957110201$ & \\
\hline & $10 \%$ level & $-2,617433721$ & \\
\hline
\end{tabular}

Fuente: elaboración de los autores. 


\section{Anexo 1. Test ADF para el caso España}

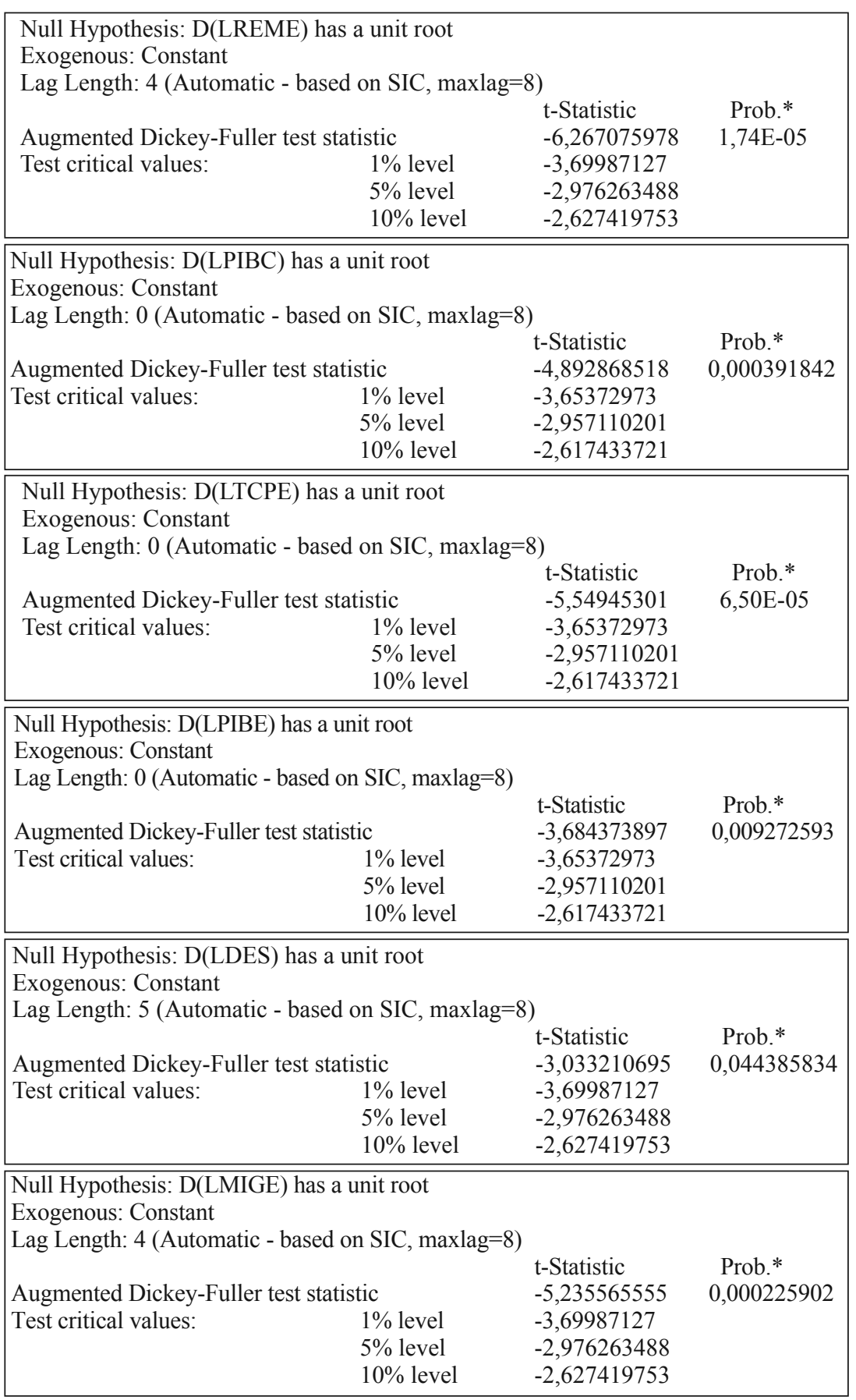

Fuente: elaboración de los autores. 
Dinámica económica de las remesas enviadas desde España y Estados Unidos a Colombia ... Andrés Mauricio Gómez Sánchez - Zoraida Ramírez Gutiérrez

\section{Anexo 3. Test de Jhoansen para Estados Unidos}

Date: 01/15/14 Time: 08:49

Sample (adjusted): 2005Q4 2013Q2

Included observations: 31 after adjustments

Trend assumption: Linear deterministic trend

Series: LREMUSA LPIBUSA LMIGUSA LDES LPIBC LTCPD

Lags interval (in first differences): 1 to 2

Unrestricted Cointegration Rank Test (Trace)

Hypothesized Trace $\quad 0,05$

No. of CE(s) Eigenvalue Statistic Critical Value Prob.**

$\begin{array}{lllll}\text { None * } \quad 0,902815789 & 186,1641634 & 95,75366142 & 3,88 \mathrm{E}-11\end{array}$

At most $1 * \quad 0,862594118 \quad 113,8986057 \quad 69,81888745 \quad 8,34 \mathrm{E}-07$

At most $2 * \quad 0,524229262 \quad 52,36930685 \quad 47,85612716 \quad 0,017740999$

$\begin{array}{lllll}\text { At most } 3 & 0,446146146 & 29,34191219 & 29,79707334 & 0,056350282\end{array}$

$\begin{array}{lllll}\text { At most } 4 & 0,275246884 & 11,02542493 & 15,49471288 & 0,209942879\end{array}$

$\begin{array}{lllll}\text { At most } 5 & 0,033171988 & 1,045774367 & 3,841465501 & 0,306481438\end{array}$

Trace test indicates 3 cointegrating eqn(s) at the 0.05 level

* denotes rejection of the hypothesis at the 0.05 level

**MacKinnon-Haug-Michelis (1999) p-values

Fuente: elaboración de los autores.

Anexo 4. Test de Johansen para Estados Unidos

Date: 01/15/14 Time: 08:53

Sample (adjusted): 2005Q4 2013Q2

Included observations: 31 after adjustments

Trend assumption: Linear deterministic trend

Series: LREME LPIBE LMIGE LDES LPIBC LTCPE

Lags interval (in first differences): 1 to 2

Unrestricted Cointegration Rank Test (Trace)

Hypothesized Trace $\quad 0,05$

No. of CE(s) Eigenvalue Statistic Critical Value Prob.**

$\begin{array}{lllll}\text { None * } & 0,892438653 & 184,4411809 & 95,75366142 & 5,58 \mathrm{E}-11\end{array}$

At most $1 * \quad 0,774848918 \quad 115,3206693 \quad 69,81888745 \quad 5,64 \mathrm{E}-07$

At most $2 * \quad 0,673815635 \quad 69,10017681 \quad 47,85612716 \quad 0,000167389$

At most $3 * \quad 0,497991316 \quad 34,3711087 \quad 29,79707334 \quad 0,013871108$

$\begin{array}{lllll}\text { At most } 4 & 0,329999 & 13,00783504 & 15,49471288 & 0,114528657\end{array}$

At most $5 \quad 0,018949662 \quad 0,593076742 \quad 3,841465501 \quad 0,441230731$

Trace test indicates 4 cointegrating eqn(s) at the 0.05 level

$*$ denotes rejection of the hypothesis at the 0.05 level

**MacKinnon-Haug-Michelis (1999) p-values

Fuente: elaboración de los autores. 
Anexo 5. Estimación modelo para EE.UU.

Dependent Variable: LREMUSA

Method: Least Squares

Date: 01/15/14 Time: 08:46

Sample: 2005Q1 2013Q2

Included observations: 34

HAC standard errors \& covariance (Bartlett kernel, Newey-West fixed bandwidth $=4.0000$ )

Variable Coefficient Std. Error t-Statistic Prob

$\begin{array}{lllll}\text { C } & -45,4878578 & 7,844421354 & -5,798752482 & 0,0000\end{array}$

$\begin{array}{lllll}\text { LPIBUSA } & 4,403796774 & 0,635173345 & 6,933220371 & 0,0000\end{array}$

LMIGUSA $\quad 0,696120224 \quad 0,152236421 \quad 4,57262606 \quad 0,0001$

$\begin{array}{lllll}\text { LDES } & 0,395176357 & 0,127641929 & 3,095976074 & 0,0044\end{array}$

$\begin{array}{lllll}\text { LPIBC } & -1,210470626 & 0,232164025 & -5,213859571 & 0,0000\end{array}$

$\begin{array}{lllll}\text { LTCPD } & 0,181658053 & 0,18445844 & 0,984818329 & 0,3331\end{array}$

R-squared $\quad 0,658067078 \quad$ Mean dependent var $\quad 5,901042678$

Adjusted R-squared $\quad 0,597007628 \quad$ S.D. dependent var $\quad 0,121836346$

S.E. of regression $\quad 0,07734376 \quad$ Akaike info criterion $\quad-2,122328534$

Sum squared resid $\quad 0,167497601 \quad$ Schwarz criterion $\quad-1,852970794$

Log likelihood 42,07958507 Hannan-Quinn criter. $\quad-2,03046983$

F-statistic $\quad 10,7774812 \quad$ Durbin-Watson stat $\quad 1,478228151$

Prob(F-statistic) 7,52E-06

Fuente: elaboración de los autores.

Anexo 6. Prueba ADF para residuales modelo Estados Unidos

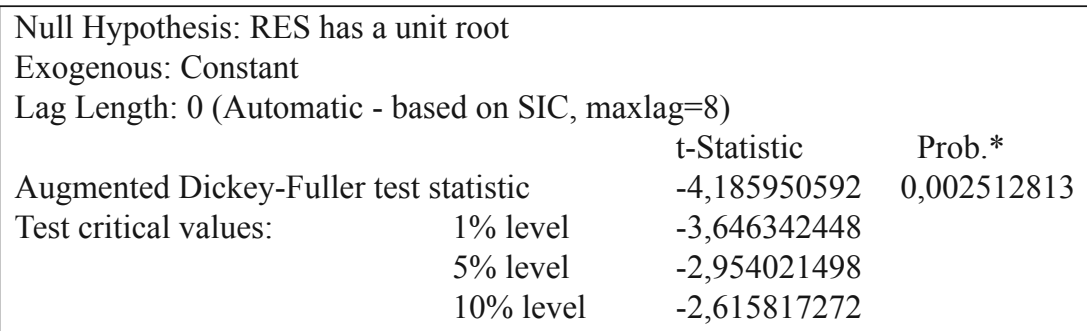

Fuente: elaboración de los autores. 
Dinámica económica de las remesas enviadas desde España y Estados Unidos a Colombia ... Andrés Mauricio Gómez Sánchez - Zoraida Ramírez Gutiérrez

\section{Anexo 7. Estimación modelo España}

\begin{tabular}{|c|c|c|c|c|c|}
\hline \\
\hline \multicolumn{6}{|c|}{ Method: Least Squares } \\
\hline \multicolumn{6}{|c|}{ Date: 01/15/14 Time: 09:00 } \\
\hline \multicolumn{6}{|c|}{ Sample: 2005Q1 2013Q2 } \\
\hline \multicolumn{6}{|c|}{ Included observations: 34} \\
\hline \multicolumn{6}{|c|}{$\begin{array}{l}\text { HAC standard errors \& covariance (Bartlett kernel, Newey-West fixed } \\
\quad \text { bandwidth }=4.0000 \text { ) }\end{array}$} \\
\hline Variable & Coefficient & Std. Error & t-Statistic & Prob. & \\
\hline $\mathrm{C}$ & $-0,999734958$ & 3,797842996 & $-0,263237569$ & 0,79429 & \\
\hline LPIBE & 0,75956549 & 0,399477558 & 7,635546215 & 0,00000 & \\
\hline LMIGE & 0,910604255 & 0,101180048 & 8,999840114 & 0,00000 & \\
\hline LDES & 1,022698908 & 0,110153408 & 9,284314731 & 0,00000 & \\
\hline LPIBC & $-1,037080103$ & 0,135864928 & $-7,633170088$ & 0,00000 & \\
\hline LTCPE & 0,525658492 & 0,128110707 & 4,103158164 & 0,00031 & \\
\hline R-squared & 0,886155599 & \multicolumn{2}{|c|}{ Mean dependent var } & 5,87190 & \\
\hline \multicolumn{2}{|c|}{ Adjusted R-squared } & 0,865826241 & \multicolumn{2}{|c|}{ S.D. dependent var } & 0,201078888 \\
\hline \multicolumn{2}{|c|}{ S.E. of regression } & 0,073654667 & \multicolumn{2}{|c|}{ Akaike info criterion } & $-2,220073324$ \\
\hline \multicolumn{2}{|c|}{ Sum squared resid } & 0,151900278 & \multicolumn{2}{|c|}{ Schwarz criterion } & $-1,950715584$ \\
\hline \multicolumn{2}{|c|}{ Log likelihood 43,74124651 } & Hannan-Qu & In criter. & & $-2,128214621$ \\
\hline \multicolumn{2}{|c|}{ F-statistic $\quad 43,58994646$} & Durbin-Wa & on stat & & 2,178266996 \\
\hline \multicolumn{2}{|c|}{ Prob(F-statistic) } & $2,32 \mathrm{E}-12$ & & & \\
\hline
\end{tabular}

Fuente: elaboración de los autores.

\section{Anexo 8. Prueba ADF para residuales modelo España}

\begin{tabular}{|c|c|c|c|}
\hline $\begin{array}{l}\text { Null Hypothesis: RE } \\
\text { Exogenous: Constan } \\
\text { Lag Length: } 0 \text { (Autc }\end{array}$ & $\begin{array}{l}\text { t root } \\
\text { ed on } \mathrm{SIC}, 1\end{array}$ & $\mathrm{~g}=8)$ & \\
\hline & & t-Statistic & Prob.* \\
\hline \multicolumn{2}{|c|}{ Augmented Dickey-Fuller test statistic } & $-6,141657595$ & $1,18 \mathrm{E}-05$ \\
\hline Test critical values: & $1 \%$ level & $-3,646342448$ & \\
\hline & $5 \%$ level & $-2,954021498$ & \\
\hline & $10 \%$ level & $-2,615817272$ & \\
\hline
\end{tabular}

Fuente: elaboración de los autores. 


\section{Anexo 9. MCE para Estados Unidos}

\begin{tabular}{|c|c|c|c|c|}
\hline \multicolumn{5}{|c|}{ Dependent Variable: D(LREMUSA) } \\
\hline \multicolumn{5}{|c|}{ Method: Least Squares } \\
\hline \multicolumn{5}{|c|}{ Date: 01/17/14 Time: 09:42 } \\
\hline \multicolumn{5}{|c|}{ Sample (adjusted): 2005Q2 2013Q2 } \\
\hline \multicolumn{5}{|c|}{ Included observations: 33 after adjustments } \\
\hline \multicolumn{5}{|c|}{$\begin{array}{l}\text { HAC standard errors \& covariance (Bartlett kernel, Newey-West fixed } \\
\text { bandwidth }=4.0000 \text { ) }\end{array}$} \\
\hline Variable & Coefficient & Std. Error & t-Statistic & Prob. \\
\hline $\mathrm{C}$ & $-0,016171035$ & 0,016453319 & $-0,982843351$ & 0,334742599 \\
\hline D(LPIBUSA) & $-0,500198931$ & 1,699278696 & $-0,294359561$ & 0,770820539 \\
\hline D(LMIGUSA) & 0,538758969 & 0,130975114 & 4,113445298 & 0,000347585 \\
\hline D(LDES) & $-0,345196801$ & 0,05198449 & $-6,640380687$ & $4,82 \mathrm{E}-07$ \\
\hline $\mathrm{D}(\mathrm{LPIBC})$ & 2,185821694 & 1,107993242 & 1,972775293 & 0,059242522 \\
\hline D(LTCPD) & 0,213955036 & 0,178899062 & 1,195953931 & 0,242507998 \\
\hline RES(-1) & $-0,813131483$ & 0,12128044 & $-6,704555861$ & $4,10 \mathrm{E}-07$ \\
\hline R-squared & 0,65987836 & Mean de & ent var & 0,007541171 \\
\hline Adjusted R-squared & 0,581388751 & S.D. depend & nt var & 0,099243205 \\
\hline S.E. of regression & 0,064210526 & Akaike info & riterion & $-2,467467773$ \\
\hline Sum squared resid & 0,107197784 & Schwarz cri & rion & $-2,150026775$ \\
\hline Log likelihood & 47,71321826 & Hannan-Qui & in criter. & $-2,360658536$ \\
\hline F-statistic & 8,407206599 & Durbin-Wat & on stat & 1,542511161 \\
\hline Prob(F-statistic) & 4,01E-05 & & & \\
\hline
\end{tabular}

Fuente: elaboración de los autores. 


\section{Anexo 10. MCE para España}

\begin{tabular}{|c|c|c|c|c|}
\hline $\begin{array}{l}\text { Dependent Variable: } \\
\text { Method: Least Squar } \\
\text { Date: } 01 / 17 / 14 \text { Tim } \\
\text { Sample (adjusted): } 2 \\
\text { Included observation }\end{array}$ & $\begin{array}{l}\text { (LREME) } \\
\text { s } \\
: 10: 19 \\
05 \mathrm{Q} 2 \text { 2013Q2 } \\
: 33 \text { after adjust }\end{array}$ & ients & & \\
\hline Variable & Coefficient & Std. Error & t-Statistic & Prob. \\
\hline $\mathrm{C}$ & 0,008893686 & 0,025249014 & 0,352238963 & 0,727498255 \\
\hline D(LPIBE) & 0,6637915 & 0,752167649 & 0,88250472 & 0,385590708 \\
\hline D(LMIGE) & 0,769487217 & 0,22331429 & 3,445758969 & 0,001946291 \\
\hline D(LDES) & $-0,976951565$ & 0,124405207 & $-7,852979709$ & $2,50 \mathrm{E}-08$ \\
\hline D(LPIBC) & $-1,768614724$ & 1,871833477 & $-0,944856873$ & 0,35343047 \\
\hline D(LTCPE) & 0,570099786 & 0,183409611 & 3,108341944 & 0,004517154 \\
\hline RES(-1) & $-0,917124405$ & 0,208257749 & $-4,403794852$ & $2,29 \mathrm{E}-05$ \\
\hline R-squared & 0,80992562 & \multicolumn{2}{|c|}{ Mean dependent var } & $-0,004550438$ \\
\hline Adjusted R-squared & 0,766062302 & \multicolumn{2}{|c|}{ S.D. dependent var } & 0,154401481 \\
\hline S.E. of regression & 0,074679529 & \multicolumn{2}{|c|}{ Akaike info criterion } & $-2,165390077$ \\
\hline Sum squared resid & 0,145002832 & \multicolumn{2}{|c|}{ Schwarz criterion } & $-1,847949079$ \\
\hline Log likelihood & 42,72893626 & \multirow{2}{*}{\multicolumn{2}{|c|}{$\begin{array}{l}\text { Hannan-Quinn criter. } \\
\text { Durbin-Watson stat }\end{array}$}} & $-2,058580839$ \\
\hline F-statistic & 18,46475939 & & & 1,938495363 \\
\hline Prob(F-statistic) & $3,01 \mathrm{E}-08$ & \multicolumn{2}{|c|}{ Durbin-Watson stat } & \\
\hline
\end{tabular}

Fuente: elaboración de los autores. 